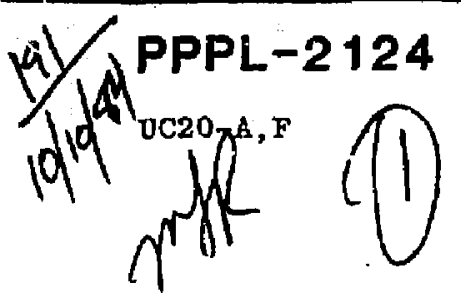

$D R \cdot 0461-8$

$$
I-17381
$$

PLASMA-MATERIALS INTERACTIONS DURING RF EXPERIMENTS IN TOEAMARS
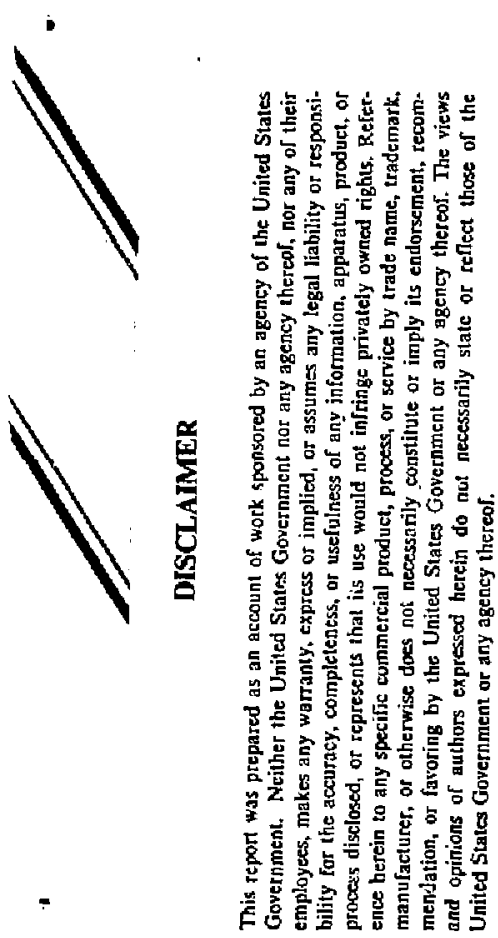

By

S.A. Cohen et al.

SEPTEMBER I984

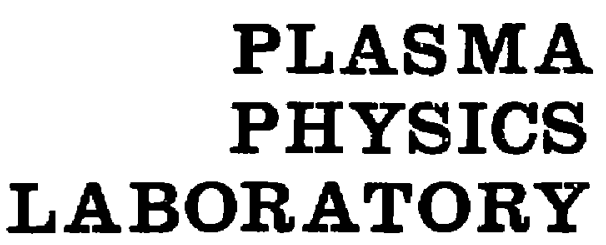

PRINCETON UNIVERSITY

PRINCETON, NEW JERSEY

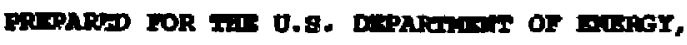
DAder contrincr D-nco2-76-C:0-3073. 


\title{
Plasma-Materials Interactions During RF Experiments \\ in Tokamaks
}

S. A. Coher, 5. Bernabei, R, Budny, T. K. Chu, P. Colestock, E. Hinnov, W. Hooke, J. Hosea, D. Hwang, F. Jobes, D. Manos, R. Motley, D. Ruzic,

J. Stevens, B. Stratton, * S. Suckewer, S. von Goeler, and R. Wilson

\author{
Plasma Physics Laboratory, Princeton University \\ Princeton, New Jersey 08544
}

$[2+2+-2.24$

Abstract

3065002215

Plasma-materials interactions studied in recent ICRF heating and lower hybrid current drive experiments are reviewed. The microscopic processes responsible for impurity generation are discussed. In ICRF experiments, improvements in machine operation and in antenna and feedthrough design have allowed efficient plasmo heating at RF powers up to $3 \mathrm{MN}$. No significant loss of energy from the plasma core due to jmpurity radiation occurs. Lower hybrid current drive results in the generation and maintenance of hundreds of kiloamperes of plasma current carried by suprathermal electrons. The loss of these electrons and their role in impurity generation are assessed. Methods to avoid this problem are evaluated.

\footnotetext{
*Johns Hopkins University
} 


\section{Introduction}

The application of high levels of radio frequency (RF) power to tokamak plasmas has produced major advances towards the realization of a steady-state thermoruciear reactor. 1 The variety of RF waves that may exist in a tokamak and the resonant character of the heating allow control of the energy deposition profile. ${ }^{2}$ Heating of a selected species, for example, electrons or a particuiar type of ion, is possible. This permits enhanced fusion reactivity, as in a two-component plasma, 3 and non-inductive current drive. 4 Another zdvantage of RF methods is the availability of nigh power components, such as power supplies and transmission lines, for several of the most desirable frequency ranges.

The aforementioned and other achievements and benefits of RF methods have not been easily attained. To a large part, this is due to plasma-materials interactions (PMI). When plasmas are irradiated with electromagnetic waves whose energy de Isity is comparable to the plasma's, changes in the particle's djstribution functions can lead to increased particle and energy loss rates to the walls and other internal structures. These may, in turn, cause the contamination of the plasma by wall matcial. This detrimental effect may be inherent to fundamental processes or to aspects of a particular experimental configuration, e.g., antenna shielding. A great effort must be expended to discover this important difference since the former problem is unavoidable while the latter is not.

The diversity of RF experiments makes an exhaustive review of PMI impractical. In this paper we concentrate on PMI during high-power ioncyclotron-range-of-frequency (ICRF) heating and lower hybric current drive (LHCD) experiments. Electron cyclotron heating, RF divertors, lower hybrid 
heating, iast-wave current drive, etc.,although in the future they may prove to be useful ways to ignite, sustain, or cleanse a tokamak reactor, are not discussed here. The main reason for their omission is tine relative scarcity of PMI-related data.

The plasma-materials interactions we consider are those that limit the coupling or RF power to the plasma and those that result in impurity generation. The first topic is generally of a technological nature - how can RF components be made to function appropriately in the vicinity of a magnetizen plasma? The second topic is concerned with a possible detrimentai side effect. Section II discusses PMI during present-day ICRF heating experiments. In II-A the general configuration of an ICRF system is described. Sections II-B and C discuss component design and preparation and impurity generation. In Section III the same subjerts are discussed for lower-hybrid current-drive experiments.

II. PMI During ICRF Experiments

A) Experimental parameters and configurations

The toroidal field of the tokamak, the Ze/m ratio of the resonant ion, and the desired harmonic of the fundamental cyclotron frequency determine th: re tuired frequency of the RF generator. The lowest frequency commonly usea on large tokamaks is about $25 \mathrm{MHz}$, mich corresponds to $\mathrm{H}$ (minority)

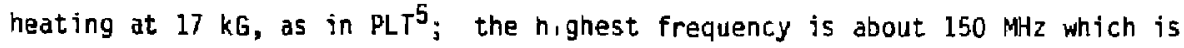
required for $H$ (2nd harmonic) heating at $100 \mathrm{kG}$, as in Alcator $C^{6}$ The free space wavelengths for these frequencies are 12 and $2 \mathrm{~m}$ respectively. Thus, for present-day machines of $1 \mathrm{~m}$ typical scale, coaxial transmission lines and 
loop antennae are necessary to bring the RF power to the machine. The transmission line is usually pressurized with $\mathrm{SF}_{6}$ to prevent voltage breakdown problems - the peak voltage being in excess of $20 \mathrm{kV}$ and the peak electric field at the surface of the central conductor being greater than ?0 $\mathrm{kV} / \mathrm{cm}$. A nigh-voltage vacuum feedthrough is then required in the proximity of the vacuum vessel. (See Figure 1.) The dimensions of the coaxial transmission line near the vacuw vessel and the feedthrough need to be small because of physical constraints imposed by port sizes and nearby field coils. This raises the required voitage stand-off ability of the feedthrough, which is frequently located near a high-voltage point in the standing wave pattern of the antennd. The maximum current and power density through the feedthrough can exceed $1 \mathrm{kA}$ and $15 \mathrm{~kW} / \mathrm{cm}^{2}$. respectively. The antennae are metallic strip lines or "loops." The "central" conductor is generally copper while the "return" conductor may be copper or stainless steel, as in the case where the vacuum vessel wall is the return. Antennae configurations which have been used include 1/2-turn end-fed Toups on the low field side 5,7 (1arge major radius), 1/4.-turn center-fed loops on the low field side, ${ }^{5}$ and $1 / 2-t u r n$ and full-turn loops on the "high field side."7 The loop is ariented in the poloidal direction for ICRF heating. The plasma is shielde: against the toroidal component of the antennae electric fields by faraday shields. The Faraday shields are sulported by ceramic ur glass (passibly MACOR) insulators.

\section{B) Component design and preparation}

The feedthrough, antennae and Faraday shields are the three components susceptible to plasma-material interactions. Extensive efforts have taken place at PPPL in the design 8 and testing of feedthroughs. Bench 
tests have shown a voltage stand-off capability in excess of $100 \mathrm{kV}$ for the design shown in Fig. 2c. The critical aspect in the design is the proper contouring of the central conductor and the dielectric to avoid high field points at their interface. With this feedthrough over 1 MW of power, the limit of the present generator, has been successfully transmitted to the PLT plasma. It should be noted that in-tokamak antenna conditioning, by pulsing with increasing levels of RF power, appears essential. Several hundred $50 \mathrm{~ms}$ duration pulses were applied to each feedthrough and antenna assembly used on PLT.

These feedthroughs are located clase to the torus near a high-valtage point. This location was chosen because of the higher gas conductance to the vessel vacuum pumps - gas desorption and surface contamination being suspected mechanisms for arc-over at feedthroughs. The possibjlity of radiation damage or plasma generation at the feedthrough due to charged or neutral particie or photon bombardment may, in the future, result in the repositioning of the feedthrough to a more distant location, perhaps at a high-current point. This will necessitate a redesign.

Various antennae configurations have been developed and tested at the major laboratories. Although early studies, notably at TFR, ${ }^{9}$ showed low field side (LFS) antennae to be inferior to high field side (HFS) antennae (Fig. 3) with respect to impurity generation, recent results both there ${ }^{10}$ and at JFT$2 M^{11}$ have confirmed the PLT finding ${ }^{12}$ that high power RF heating can occur with little plasma contamination even if the antennae are on the low field side. In addition, first results ${ }^{5}$ from PLT have shown ittle difference in impurity generation between center-fed 1/4-turn and end-fed 1/2-turn LFS antennae. Impurity generation will be discussed in more detail in the next section. 
In 1965 Yoshikawa ${ }^{13}$ recognized that Faraday shields were essential to proper antenna operation. They define the electric field vector, thus determining the waves generated in the plasma, and also whether a sheath will form at the antenna due to rectification by the plasma. (The importance of this to impurity generation will be discussed later.) Faraday shieids have been constructed of various materials, including stainless steel, titanium and graphite. Their thicknesses range from $0.1 \mathrm{~mm}$ to nearly $10 \mathrm{~mm}$. In present experiments, the heat load on the Faraday shields, due primarily to plasma bombardment, still allows them to be uncooled. Future experiments, with several seconds pulse length; will undoubtedly require activeiy cooted shields. Proper preparation of the shields usually entails mechanical smoothilg and rourding of the edges, degreasing, and high-temperature bakeouts $\left(400^{\circ} \mathrm{C}\right.$ for stee 1 and $1100^{\circ} \mathrm{C}$ for graphite) in vacuum.

\section{C) Impurity generation processes}

Before discussing the mechanisms responsible for impurity generation, it is proper to assess the importance of impurities in present ICRF heating experinents. Although some ICRF experiments had eariier been plagued with impurity problems caused, in part, by inadequate well and component designs and conditfoning techntques and tokamak operating routines, all major experiments have now achieved conditions wherein, for Mw heating levels, efficient ion heating is attained, and the radiated power from impurities in the plasma care is less than $10 \%$ of the power input to the core. The radiative power loss from the entire plasma is due to contamination by both high and low $z$ impurities. As shown in kig. 4, radiation from the plasma is enitted primarily from the periphery 5 by low $z$ contaminants, and 
accounts for about $30 \%$ of the total input power. This is generally considered a desirable mode of operation since it distributes the heat load uniformly on the walls and reduces direct localized plasma bombardment of the walls and limiters. The amount of radiated power scales linearly with RF power ${ }^{14}$ (Fig. 5). Modelling of the impurity radiation in $\mathrm{TFR}^{10}$ gives central metal ion densities of $\sim 2 \times 10^{10} \mathrm{~cm}^{-3}$ and carbon and oxygen ion densities of $\sim 2 \times 10^{12} \mathrm{~cm}^{-3}$ in a plasma with $n_{e}(0)=1.1 \times 10^{14} \mathrm{~cm}^{-3}$. This represents a $z_{\text {eff }}-2.5$ and a $20 \%$ depletion of hydrogenic ions. Both the high $Z_{\text {eff }}$ and the deuteron depietion would severely impact a reactor. Thus, although high and low $z$ impurities do not significantly affect the power $r$ alance in the present multi-MH experiments, it is necessary to understand their origins to ensure that future experiments at higher powers and longer pulse are not impeded.

The four primary microscopic processes by which ICRF heating can cause impurity generation are arcing, evaporation, ion sputtering, and charge exchange neutral sputtering. Arcing is judged to be of little consequence in a well-conditioned ICRF system based on the time behavior of the impurity radiation. Indeed, photographic recordings in PLT of the antennae structures during high-power heating show no flashes indicative of arcs. Evaporation, too, is of little consequence except during low density conditions where severe runaway electron bombardment may occur. This situation may not be true in the near future when long-pulse nigh-power ICRF heating systems are put into operation. Then both the limiter (or divertor) heat removal systems and the antenna structures will require active cooling.

Sputtering by ions has been judged by several groups 10,11 to be ait imfortant cause of impurities. Ions which leave the main body of the plasma impact on the material surfaces nearest the edge plasma. In addition to the limiters, the antennae are placed near the plasma edge because the coupling 
between the antenna and the plasma improves as the distance between them is reduced, the scale distance being of order $-1\left(k_{\perp}\right)^{-1} \simeq 5 \mathrm{~cm}$. Thus ICRF antennae are immersed, of necessity, in the edge plasma at a distance of $\sim 5 \mathrm{~cm}$ outside the limite: radius, The calculated and experisnental loading resistances for the TFR ${ }^{10}$ HFS side antenna, shown in Fig. 6, clearly indicate the change in coupling with distance between the antenna and the plasma.

The edge plasma electron temperature and density are shown in Figs. 7 and 8 for ICRF heating of TFR 10 at $\pi_{e} \sim 1 \times 10^{14} \mathrm{~cm}^{-3}$, and $I_{p} \sim 200 \mathrm{kA}$. Both $\mathrm{T}_{e}$ and the density scrape-off distance, $\lambda_{n e}$, are seen to double for $P_{r f} \sim 300$ kW. Similar results have been seen on PLT'15 and ATC ${ }^{16}$ for $\Delta \lambda_{n_{e}}$, but not $\Delta T_{e}$. Power dependences of $\Delta T_{e}$ and $\Delta \lambda_{n e}$ have been studied in TFR and JFT-2M and found to be similar. Results from the latter are shown in Fig. 9. For the parameters $\lambda \sim 1 \mathrm{~cm}$ and $\mathrm{T}_{\mathrm{e}} \sim 5 \mathrm{eV}$, the stored energy in the plasma edge is only $\leqslant 10$.

The ions which strike the limjters, RF antennae, and walls impact with an energy equal to the sum of their kinetic energy plus $Z$ times the sheath potential. The sheath potential may be several (typically four) times $T_{e}$, or it may reach a substantial fraction of the peak antenna voltage. This latter condition exists if plasma rectification of the RF occurs such as in the absence of grounded Faraday shields. The jons which strike the limiters can be categorized into three classes: thermal hydrogenic, thermal impurities, and suprathermal hydrogenic. Using probes at the limiter radius, the edge plasma ion temperature during earlier experiments has been measured to be 20 $200 \mathrm{eV} .17,18$ However, no data have been presented for the highest (3 MH) powers recently attained. Using the TFR edge parameters and assuming $T_{j}(a)=$ $50 \mathrm{eV}$, a deuterium plasma, an impurity confinement time of $20 \mathrm{~ms}$, sputtering yields for clean metals, 19 and a poloidally uniform flux, TFR estimates the 
volume averaged impurity density from a carbon ring limiter to be $5 \times 10^{11} \mathrm{~cm}^{-}$ 3, and $5 \times 10^{10} \mathrm{~cm}^{-3}$ for a steel ring limiter. If $T_{j}(a)=175 \mathrm{eV}$ the carbon density would be $10 \times$ higher and the iron density 100x higher. Because of this agreement (factor of 2) between these estimated and the observed impurity levels, and also because of a positive correlation between fmpurfty species and Faraday shield material, the TFR group confirmed the PLT conclusion that thermal hydrogenic ion sputtering of B-normal surfaces, especially the limiter and Faraday shields, is the main cause of their impurities.

The JFT-2M teamll has reached a somewhat different conclusion because of the power dependence of the impurity concentrations and a positive correlation between light $(\mathrm{C}, \mathrm{O})$ and heavy $(\mathrm{Fe}, \mathrm{Ni})$ impurity levels in ICRF-heated discharges. They describe the influx of metal impurities as being due to the impact of multiply-charged $C$ and 0 ions. Only at the highest RF power is proton sputtering important. In contrast, the TFR team has purposely contaminated their discharge with $\mathrm{Ne}$ in an attempt to see this phenomenon, 9 but they saw no significant $(<10 \%)$ change in the metal impurity level.

Manos et al.,20 and Hammett et al.,21 have investigated the loss of suprathermal jons from the PLT. In 2nd harmonic $\mathrm{H}^{+}$heating they see the loss of $\sim 90 \mathrm{keV}$ banana trapped ions. No similar losses are observed for minority heating of $\mathrm{He}^{3}$ in a $\mathrm{D}$ plasma. The loss during 2 nd harmonic $\mathrm{H}^{+}$heating is not poloidally symetric, but is concentrated at the outside midplane position.22 The direct sputtering by these energitic tons is estimated to be unimportant for impurity generation, both because of the low yield $\left(10^{-4}\right)$ and the low flux $\left(1 \times 10^{18}+4 \times 10^{19} \mathrm{~s}^{-1}\right)$. However, a synergistic interaction between the heat deposited by these energetic ions and the momentum deposited by thermal ions may cause enhanced evaporative sputtering. 22 
The final mechanism possibly responsible foi impurity generation is sputtering by neutrals. A low energy neutral atom spectrameter ${ }^{23}$ has been used on PLT to study the efflux of charge exchange neutrais during ICRF experiments. 15 The efflux increases at a rate of $\sim 10^{15} \mathrm{~cm}^{-2} \mathrm{~s}^{-1} \mathrm{MH}^{-1}$ during both and harmonic and minority heating. In Fig. 10 one can see that the increase in flux, $\Delta \Gamma$, is toroidally sumetric. The cause of this efflux is the increase of ton censity near the vessel wall, which leads to enhanced neutralization and a higher neutral density. Although the rise in $n_{1}(a)$ may be due to entanced transport, anjther mechanisin can also explain the increase in jon density. From ray iracing calculations, we estimate that $1 \%$ of the if power is absorbed in the edge. This increases the eiectron temperature which increases the ionization rate of neutrals and ion density in that region, quantitatively in agreement with the observed rise in $n_{j}$.

The charge exchange measurements show an fncrease across the entire spectrum, from 20 to $50,000 \mathrm{eV}$, with the largest jercentage increase at the highest energies (Fig. 11). Using the sputtering yields for clean metals, the increase in flux can account for the observed increase in wall material found during ICRF heating. Flgure 12 shows a portion of the U.V. spectrum before and during ICPF hicating. Increases in $T A$ and $F e$, presumably from the wall, are evident. Increases in $C$ and 0 , presumably from the limiter, are also seen. The charge exchange efflux may also be responsible for the sputtering of Faraday shield material previously coated around the tokamaks by ion sputtering or evaporation. The charge exchange efflux is observed to have an inverse dependence with plasma current. Ion heating efficiency behaves in an opposite fashion, i.e., in PLT good ion heating only occurs for $I_{p} \sim 300 \mathrm{kA}$. 
In sumary, nigh power heating of tokamak plasm. by ICRF teciliniques has increased the central ion temperature at a rate between 3 and $6 \mathrm{eV} / \mathrm{kW} \cdot \mathrm{IG}^{13}$ $\mathrm{cm}^{-3}$. To achleve this, major improvements had to be made in feedthrough and antenna designs. Operation with a "good" target plasma is also essential, the main parameter being a high plasma curreit. The impurity flux into these discharges has not affected the power balancs in the plasma core, but does cause enhanced radiation from the plasma periphery and some depletion of the hydrogen tons in the core. The structures which are the sources of these impurities are the limiters, Faraday shields, other objects within a few cent!meters of $r=a$, and the walls. The scructures close to the plasma are sputtered by thermal ion bon, ardnent and possibly multiply charged impurities. The wall is sputtered by charge exchange neutrals. Figure 13 shows the effects on impurity leveis of changing Faraday shield material in PLT.

III. PMI During LHCD Experiments

\section{A) Experimental parameters and conflgurations}

Lower hybrif waves in a plasma may be absorbed by electron Landau damping. This transfer of energy and momentum to electrons which resonate with the lower hybrid waves' phase velocity has enabled the generation 24 and sustentation 25 of currents in tokamak plasmas. To propagate, the frequency of lower hybrid waves must be above the lower hybrid resonance frequency and below the electron cyclotron and plasma frequencies. For present tokamaks this is in the range $200 \mathrm{MHz}+30 \mathrm{GHz}$. Powerful generators are available in the middle of this range at $f=800 \mathrm{MHz}, 1.5 \mathrm{GHz}, 2.45 \mathrm{GHz}$, and $4.6 \mathrm{GHz}$, at 
which frequencies the free space wavelengths are $37,20,12$, and $6.5 \mathrm{~cm}$ respectively. Thus waveguides ure appropriate transmission lines to carry the power to the machines, and waveguide launchers are suftable antennae.

The requirement that $\rightarrow 1 \mathrm{WW}$ of RF power must be injected through $\sim 20 \mathrm{~cm}$ ports sets the power density at $\leq 10^{4} \mathrm{kw} / \mathrm{cm}^{2}$ and the peak electric field at $\$ 4 \times 10^{3} \mathrm{~V} / \mathrm{cm}$. The transmisston line from the generator to the vicinity of the tokamax is pressurized with ary air to prevent high voltage breakdown. A waveguide window vacuum break is required in place of the coaxial feedthrough used in ICRF. The RF power is finally brought to the vacuum vessel through an array of closely spaced waveguides. Phasing the array allows one to launch the lawer hybrid waves predominately in one direction for current drive. Figure 14 shows a schematic of the major components.

The current drive efficiency, as derived by Fisch, 26 can be written

$$
\frac{I(M A)}{P(M N)}=\frac{.35 E_{100}}{R \quad \bar{n}_{20}},
$$

where $E$ is the average energy of the resonant electrons (in units of $100 \mathrm{keV}$ ), $R$ is the major radius (in meters), and $\tilde{n}_{20}$ is the average density (in units of $10^{20} \mathrm{~m}^{-3}$ ). Because of this inverse dependence on $n$ and a density limit, $n_{c}$, on wave propagation, 27 current drive experiments are usually run at lower densities than the peak value attainable in many machines. Present experiments 28 indicate that the density limit increases with $\omega^{2}$. In PLT, for example, $800 \mathrm{HHz}$ LHCD experiments are carried aut below a critical density $\pi_{\mathrm{C}}$ $\simeq 8 \times 10^{12} \mathrm{~cm}^{-3}$; in Alcator $C$, LHCD 6 is possible at densities up to $\pi_{c}=1 \times$ $10^{14} \mathrm{~cm}^{-3}$ because a frequency of $4.6 \mathrm{GHz}$ is used. At these reduced densities, 
both the energy and particie confinement times are also below their peak values. This affects the power loading on the vessel components through both the loss of thermal plasma and the lower-hybrid-generated tail electrons. At the nighest powers yet used, $1 \mathrm{MW}$ in Alcator $C$ and $\sim 600 \mathrm{~kW}$ in PLT, the central electron temperature was $\sim 1 \mathrm{keV}$ and the energy canfinement time was $\sim 10 \mathrm{~ms}$. The average energy of the electron tail was $100 \mathrm{keV}$.

\section{B) Component design and preparation}

The waveguide array (launcher), the waveguide walls, and the RF window are the main RF components susceptible to plasma-surface interactions. The launcher is immersed in the edye plasmis to a position where $w<w_{p e}\left(r_{e} z 10^{11} \mathrm{~cm}^{-3}\right.$ for PLT) in orger that a propagating wave be generated. This positions the array about $2-2 \mathrm{~cm}$ outside the limiter. The coupling of power to the plasma is critically dependent on this distance, as shown in Fig. 15. The front face of the array is curved to match the minor radius of the plasma. No systematic study of inis feature has jet been published. We note that this shaping and the sensitivity to $\pi_{e}$ make the plasma position a critical parameter to control.

In a fusion reactor the RF windows will be placed far from the tokamak to avoid radiation dahage. (Here comnercial high power klystron windows can be used.) This, however, leads to evacuated waveguides passing through regions of low magnetic field where $\omega=\omega_{c e}$. Here the phenomenon of multipactoring, secondary electron amplification, will take place if the secondary electron emission coefficient, $\delta$, of the waveguide walls exceeds unity. This problem has been addressed by several groups. For the present experiments special RF windows have been manufactured both at the major laboratories and private 
companies to allow the window array to be as close to the plasma as possible. Multipactoring, although still a problem, is more readily avoided.

Recently the ASDEX team ${ }^{29}$ has produced a fern-like geld coating with o< 1 at all energies and all angles of electron impact. The angular dependence of $\delta$ is important because non-normal electron impact will occur for cyclatron harmonic multfoactoring and for fast (lower hybrid) wave launch. Though s of solid gold is 1.4, the parous gold structure reduces the probability of secondary electron re-emission (Fig. 16a). A waveguide array has been Aucoated and operated both on a test stind ${ }^{30}$ and in ASDEX. 31 The results are excellent. Little in-tokamak conditioning was iequired to achleve a power throughput of $700 \mathrm{~kW}$.

Different coatings 32 were developed earlier at PPPL to handle normal electron incidence. These coatings, ejther pyrolized glyptal or electrophoreticalty deposited carbon in pyrolized glyptal, have $s<1$ at all energjes $^{33}$ for normally incident electrons (Fig. 15b). In the PLT experimental configuration, the window is in a magnetic field high enough so that cyclotron haımonic multipactoring is unimportant. Thus all electrons rit waveguide surfaces at near normal incidence. The res 'ts for this coating are excellent. The difference in reflection coefficient vs power are shown in Fig. 17 for waveguides with and without this coating.

In addition to multipactoring, gas evolution fron waveguide walls can result in ionization and cause plasma generation and wave cut-off. The earlier methods to treat this problem had been to apply coatings of clean low$z$ metals, such as titanium. Sci dists at Grenoble ${ }^{34}$ have developed $¥$ varient to coating by using glow discharge cleaning to remove the sorbed gas layers. Their results with both $\mathrm{Ti}, \mathrm{Cu}$, and stainless steel wavegujdes have been 
remarkable. Record power densities, $3512 \mathrm{~kW} / \mathrm{cm}^{2}$, and electric fields, 10 $\mathrm{kV} / \mathrm{cm}$, have been achieved in a iest bed. Lowering of $\delta$ has also been achieved. This result has been interpreted as being due to increased surface roughness induced by the argon glow discharge.

\section{C) impurity generation processes}

The usual effects of impurities in plasmas are to reduce the energy confinement time via radiation and to decrease the hydrogen concentration at constant $\forall$. In present LHCD experiments nejther of these is important because of the low density which results in little electron impact excitation and no $B$ linit. However, two important impurity-related effects are observed during LHCD. The first is a decrease in current drive efficiency, possibly due to enhanced onmic dissipation by the slideaways or to surface losses via collisinnal damping of the wave. In Alcator $C^{6}$ a $40 \%$ lower current drive efficiency is measured for discharges with $C$ or SiC limiters than for those with Mo limiters. The second effect is a complete cessation of current drive when $n_{e}$ rises abova its critical value, such as by the addition of the electrons from the impurities. This latter effect is shown in Fjg. 18. A carbon influx raises $n_{e}$ during this particular experiment. By 450 ms into the discharge, the current ramp-up rate produced by $300 \mathrm{kH}$ net of LH power has decreased to zero. Methods to avoid both of these problems have been recently set forth and will be discussed at the end of this section.

The impurity generation processes to be evaluated for LiICD are the same as for ICRF: arcing, evaporation, ion sputtering, and charge exchange sputtering. Arcing in the main vessel is rarely seen and is not considered a problem. Observations of apparent arcs occuring near the waveguide mouth have been made. The arcs are irreproducible and infrequent. 
Evaporation is judged to be a major cause of impurity generation. LHCD results in the formation of an energetic electron tafl of $100 \mathrm{keV}$ typical energy (Fig. 19). The confinement of energetic electrons has been measured by Barnes.36 For 0.4-1.0 MeV runaways generated inductively, Barnes finds a confinement time of 2-6 ms (Fig. 20). Preliminary results ${ }^{37}$ on LH generated tail electrons give a somewhat longer confinement time, about 25 ms. The slowing down time on the background thermal plasme for these electrons is about $20+200 \mathrm{~ms}$. The point, then, is that some energetic electrons will leave the plasma. In addition, acceleration of already energetic electrons may occur in the edge plasma thus increasing the likelihood of the loss of energetic electroris. It has been noted 36,39 that the nigher $v_{\|}$of a specles the shorter the scrape-off distance. For electrons of 100 keV parallel energy, the scrape-off distance is about $0.1 \mathrm{~mm}$. The net result is a concentrated heat load by the lost energetic electrons on the material abject nearest the plasma edge. In PLT this is generally a carbon limiter. Photographic recordings using standard TV/video and film techniques have clearly shown the formation of an incandescent hot spot on the PLT limiters. The not spot can be moved from the top to the bottom to the outside midplane limiter by shifting the plasma position appropriately. The surface temperature, $T_{5}$, has been estimated from the spot brightness to be $T_{5}=$ $2500^{\circ} \mathrm{K}$. At this temperature evaporation can readily cause the observed carbon contamination in the plasma.

Ion sputtering is estimated to be a less important impurity source, both from the limiters and the waveguides. At the low densities and short particle confinement time, these impurity densities should be $-10^{2}$ times lower than in ICRF-heated discharges. In addition, in test bed experiments 40,41 the effect of the wave directly in front of the waveguide has been evaluated. The plasma 
density has been found to decrease at $\mathrm{RF}$ power levels greater than $1 \mathrm{~kW} / \mathrm{cm}^{2}$. This occurs because the "RF pressure" becomes comparable to the electron pressure. A positive potential also builds up. The net effects should be a decrease in the ion flux to the waveguide and reduced ion sputtering.

Charge exchange sputtering has been evaiuated on PLT42 using neutral particle diaynostics. For $10^{12}<\mathrm{n}_{\mathrm{e}}<10^{13} \mathrm{~cm}^{-3}$ no large increase in the charge exchange outflux has been abserved during LHCD. At these low densities the charge exchange flux is toroidally uniform and has an average energy twice higher than during higher density $\left(10^{13}<h_{e}<10^{14} \mathrm{~cm}^{-3}\right)$ operation. The predicted Fe concentration is $\sim 5 \times 10^{10} \mathrm{~cm}^{-3}$, giving $Z_{\text {eff }}=3$.

Thus the two main causes of impurities are evaporation due to energetic electron impact and sputtering due to charge exchange hydrogen bombardment. This latter process will become less important at higher densities, in part because of the drop in average energy wfth increased plasma opacity, and in part due to the increase in particle confinement time. The first process, though, has been tentatively identified in Alcator $C$ which already operates at the high densities envisioned for reactors. It thus appears that energetic slideaways will be lost from tokamaks with reactor-?ike parameters.

To reduce the temperature rise on a small area of the limiter, the plasma could be moved thus shifting the tangency point. However, this will alter the LH coupling. The converse, to move the limiter, has recently been suggested and tried on PLT. The limiter shape must be specially tailored so that the tangency point is near the limiter clrcumference. Then, by rotating the limiter, for example, the heat load can be readily distributed over a larger area. The successful implementation of this concept has been reported. 43 
Acknowledgments

We wish to thank J. Adam, G. Tonon, M. Keilhacker, D. Eckhartt, U. Jacqujnot, and K. Odajima for sending versions of unpublished papers. This work was supported wy the U.S. Department of Energy Contract No. DE-ACO2-76CH0-3073. 
References

1 D. Hwang and J. R. Wilson, Proc. IEEE 69, 1030 (1981).

2 p. Colestock et al., in Proceedings of the. $2^{\text {nd }}$ Joint Grenoble-Varenia International Symposium on Heating in Toroidal Devices Como, 1980, (CEC, Brusse15, 1981) Val. I, p. 471.

${ }^{3}$ J. M. Dawson, H. P. Furth, and F. H. Tenney, Phys. Rev. Lett. 26, 1156 (1971).

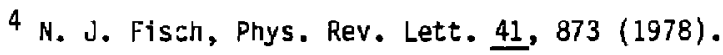

5 J. Hosea et al., Proc. Fourth International Symposium on Heating in Toroidal Plasmas, Rome, 1984 (to be pubilished).

6 M. Porkolab et al., Proc. Fourth International Symposium on Heating in Toroidat Plasmas, Rome, 1984 (to be published).

7 TFR Group, EUR-CEA-FC-1219 (March 1984) (Internal Report)

8 D. Hwang et aㅡ., J. Va:. Sci. Technol. 20, 1273 (1982).

9 TFR Group, in Proceedings of the llth European Conference on Controlled Fusion and Yiasma Physics, Aachen, W. Germany, 1983, (Eur. Phys. Soc., Petit-Lancy, Switzerland, 198.3) p. 165. 
10 TFR Group, Proc. Fourth International Symposium on Heating in Torofdal Plasmas, Rome, 1984 (to be published).

$11 k$. Odajima et al., Proc. Fourth International Symposium on Heating in Toroidal Plasmas, Rome, 1964 (to be published).

12 D. Hwang et al,, in Plasma Physics and Controlled Nuclear Fusion Research Baltimore, 1982 (IAEA, Vienna, 1983) Vol. II, p.3.

13 3. Ycshikawa, M. A. Rothman, and R. M. Sinclair, Phys. Rev. Lett. 14, 214 (1965); Princeton Plasma Physics Laboratory Report No. MATT-373 (1965).

14 B. Stratton et al., Nucl. Fusion (in press).

15 S. Cohen e: al., (Unpublished).

$16 \mathrm{H}$. Hsuan et al., in Proceedings of the 3rd Topical Conference on RF Plasma Heating, Pasadena, 1978 (California Institute of Technology, Pasadena, CA) p. CB.

17 G. Staudenmaier, P. Staib, and W. Poschenrieder, J. Nucl. Mater.93 \& 94, 121 (1980); P. Staib, J. Nucl. Mater. 111 \& 112, 109 (1982).

18 S. A. Cohen, H. F. Dylla, W. R. Wampler, and C. W. Magee, J. Nucl. Mater. $93 \& 94,109(1980)$. 
19 J. Bohdansky, J. Roth, and H. L. Bey, J. App1. Phys. 피, 2861 (1980).

20 D. Manos, R. Budny, T. Satake, and S. A. Cohen, J. Nucl. Mater. $111 \& 112$, $130(1982)$.

21 G. Hammett et al., Bull. Am. Phys. Soc. 28, 1129 (1983).

22 D. Manos et al., J. Vac. Sci. Technol. (in press).

23 D. E. Voss and S. A. Cohen, Rev. Sci. Instrum. 53, 1696 (1982).

24 J. Stevens et al., Princeton Plasma Physics Laboratory Report No. PPPL-1977 (1983).

25 F. Jobes et al., Phys. Rev. Lett. 52 1005 (1984).

26 N. J. Fisch, Phys. Rev, A 24, 3245 (1981).

27 W. Hooke et al., in Proceedings of the 11 th European Conference on Controlled Fusion and Plasma Physics, Aachen, W. Germany, 1983 (Eur. Phys. Soc., Petit-Lancy, Switzerland, 1983) p. 133.

28 F. Alladio et al., Proc. Fourth International Symposium on Heating in Toroidal Plasmas, Rome, 1984 (to be published).

$29 \mathrm{H}$. Derfler et al., Proc. Fourth International Symposium on Heating in Toroidal Plasmas, Rome, 1984 (to be published). 
30 F. Leuterer et al., Proc. Faurth International Symposium on Heating in Toruidal Plasmas, Rome, 1984 (to be published).

31 D. Eckhartt et al., Proc. Fourth International Symposium on Heating in Toroidal Plasmas, Rome, 1984 (to be published).

32 נ. Timberlake et al., U. Vac. Sci. Technol. 20, 1309 (1982).

33 D. Ruzic et al., J. Vac. Sci. Technor. 20, 1313 (1982).

34 G. Rey et al., in Proceedings of the 3rd toint Varenna Grenoble International Symposium on Heating in Torotdal Devices, Grenoble, 1982 (CEC, Brussels, 198 ) Vol. 28, p.1165.

35 G. Tonon et al., Proc. Fourth International Symposium on Heating in Toroidal Plasmas, Rome, 1984, (to be published).

36 C. W. Barnes, Ph.D. Thesis, Princeton (1981).

37 J. D. Strachan, private communication.

38 H. Selberg et al., Bull. Am. Phys. Soc. Vol. 28, p. 1092 (1983).

39 S. Cohen et a1. Nucl. Fusion 21, 233 (1981),

40 R. Mot ley, Phys, Rev, Lett, 77A, 451 (1990). 
43. S.A. Cohen et al., Princeton Plasma Fhysics Laboratory Report No. PPPL-2123 (1984) 
Figure Captions

1. Schematic of an ICRF 1/2-turn end-fed antenna system. This design, used in PLT, emplays ceramic feedthroughs near the vacuum vessel. Faraday shields, typically of stainless steel, cover the central conductor.

2. Cross section of three feedthroughs designed for PLT. The design shown at the bottom has successfully stood off $100 \mathrm{kV}$ in a test stand and transmitted 1 MW of power at $25 \mathrm{MHz}$ into PLT plasmas (Ref. 8).

3. a) View of the TFR 1/2-turn end-fed LFS antenna. b) Details of the cross section. The main improvements in this design are carbon rails (4) which protect the sides of thick Faraday shields (3). The return conductor is indicated as (1) in the Figure (Ref. 9).

4. Total radjated power end abel inverted profiles during ${ }^{3}$ He minority heating at $P_{R F} \sim 700 \mathrm{kH}$. The profiles were taken about $200 \mathrm{~ms}$ after the RF was turned on (Ref, 5).

5. Total radiated power and b-ightness of several impurity lines versus RF power during second harmonic heating at $\pi_{e}=3.8 \times 10^{14}, \mathrm{~B}_{\mathrm{T}}=14 \mathrm{kG}$ (Ref. 5).

6. Loading resistance of the JET-TFR antenna versus the distance botween the plasima boundary and the central conductor (- theory, 0 experiment) (Ref. 7). 
7. Electron temperature profjle measured in the TFR plasma edge witr jouble Langnivir probes (Ref. 7).

8. Electron density profiles in the TFR scrape-off plasma as measured for onmic and ICRF-heated plasmas. The limiter is at 19.5 cm (Ref. 7).

9. Power dependence of the electron density and temperature in the JFT-2M edge plasma. The background levels for $T_{e}$ are Indicated for both neutral-beam injection (NBI) and ohmjc heating (OH) (Ref. 11).

10. Chargs exchange $0^{\circ}$ efflux as a function of time for three cases during ICRF minority heating of $\mathrm{D}-\mathrm{He}^{3}$ plasmas with $\mathrm{P}_{\mathrm{RF}}$ \& 1 MW. The flux is integrated over the energy range 25 to $1000 \mathrm{eV}$. $\mathrm{A}$ and $\mathrm{B}$ are observations away from the limiters. $C$ is obser:ations near an auxiliary limiter (Ref. 15).

11. Charge exchange flux spectra in PLT for ohmically heated and ICRF-heated $\left(P_{\mathrm{RF}}\right.$ \& $\left.1 \mathrm{MH}\right)$ plasmas.

12. Spectra of the 110 to $175 \mathrm{~A}^{\circ}$ region befare $(t=400 \mathrm{~ms}$ ) and during ( $t=$ 600 ms) ICRF heating in the $H^{+}$minority regime at $P_{R F}=2 \mathrm{Hi}$ in $\mathrm{HLT}$. ine antennae had titanium Faraday shields (Ref. 14).

13. A comparison of the total titanium and jron densities before and during ICRF heating in PLT. As indicated, the antennae had either titanium or stainless steel Faraday shields (Ref. 14). 
14. Schematic of a typical lower hybrid system. The waveguide section between the generator and the window may be pressurized with dry $\mathrm{N}_{2}$ or $\mathrm{SF}_{6}$ to prevent arcing.

15. Calculated reflection for an 8-waveguide array launching $n_{y} \cong 1.8$ spectrum into a plasma with edge density of $6 \times 10^{10} \mathrm{~cm}^{-3}$. The coupling decreases with increasirig separation between the launcher and the piasma.

16. Secondary electrun yields for (a) porous gold (Ref, 29) and (b) pyrolized glyptal (Ref. 33). In (a) $\Delta$ - normal incidence and $x-80^{\circ}$ from normal.

17. Coupling versus RF power ( $800 \mathrm{MHz}$ ) per waveguide in PLT for a waveguide with stainless steel walls (•) and one with stainless steel walls coated with pyrolized giyptal $(0, \Delta)$. For the uncoated waveguide $R+1$ for powers above $60 \mathrm{kH}$.

18. Time evolution of the electran density, plasma current, and CV radiation during a LHCD discharge in PLT. The RF power was on from 400 to 600 $\mathrm{ms}$. The carbon influx is caused by localized evaporation from a carbon limiter.

19. Spectra of X-ray photon emission from PLT during LHCD experiments. The relative phasing of the waveguide array results in a different energy distribution for the energetic electrons responsible for the $x$-ray emission. 
20. Confinement tine versus energy of electrons in PLT (Rer. 36). 


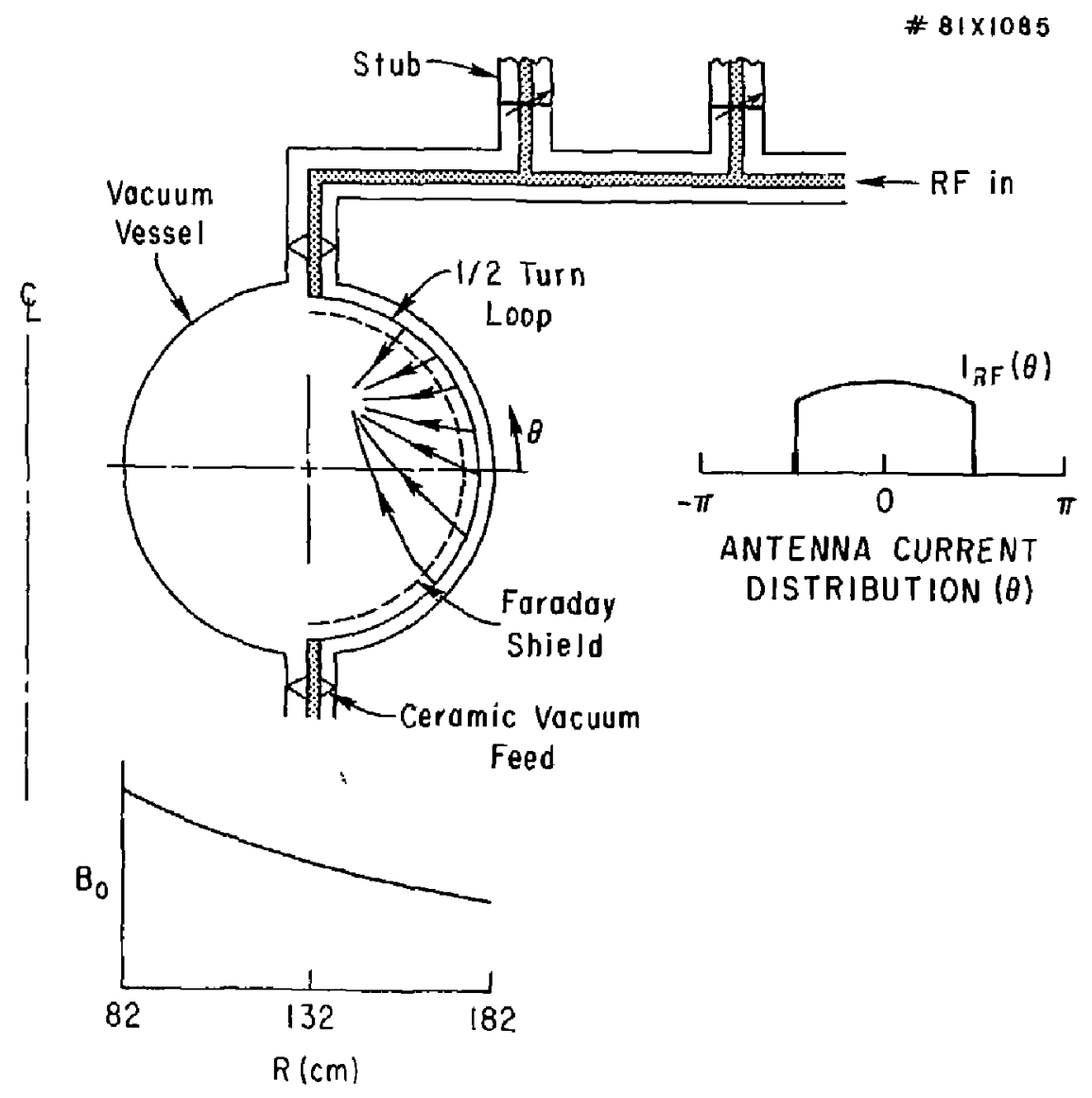


\# 8Ixtros
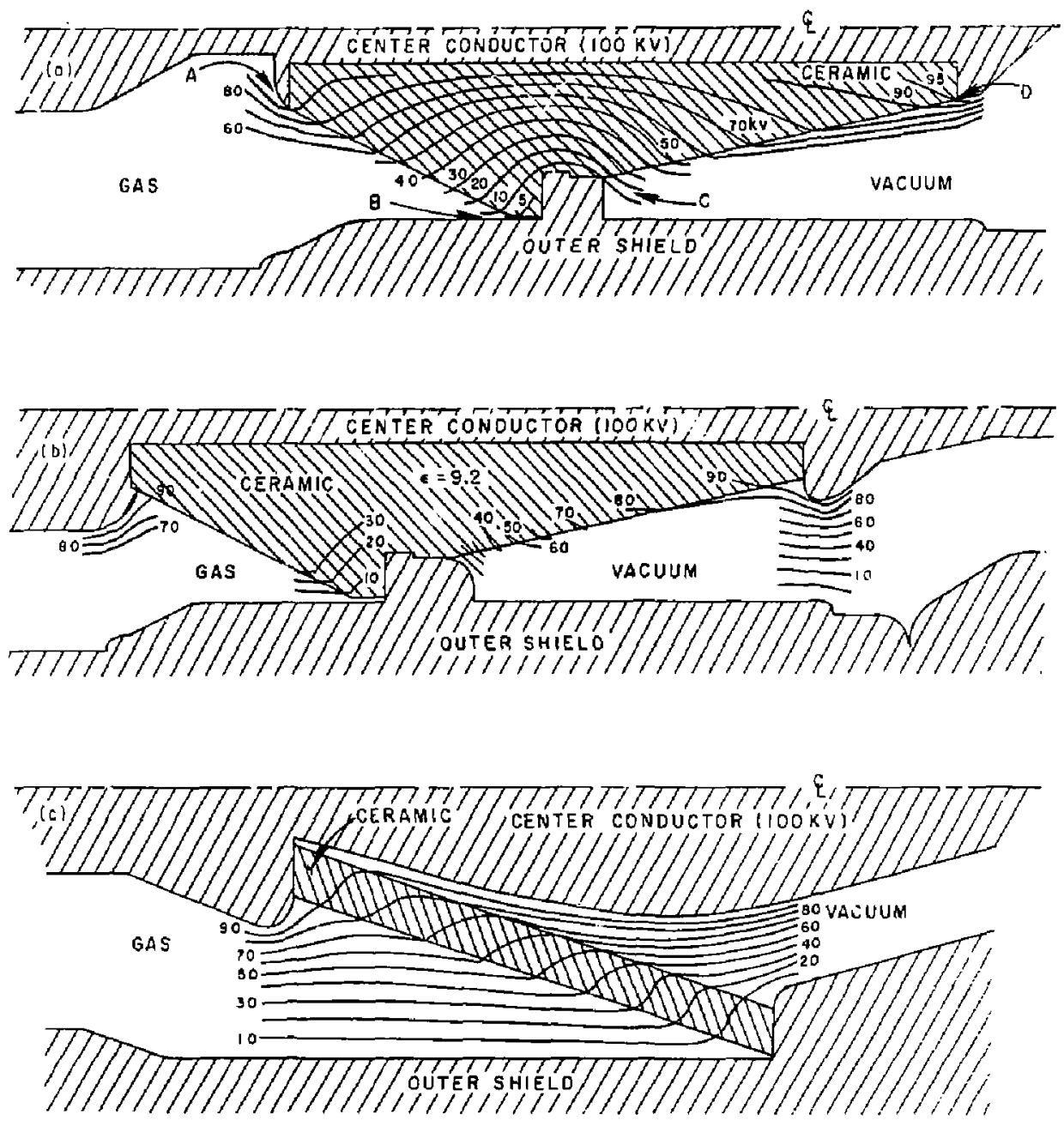

Fig. 2 


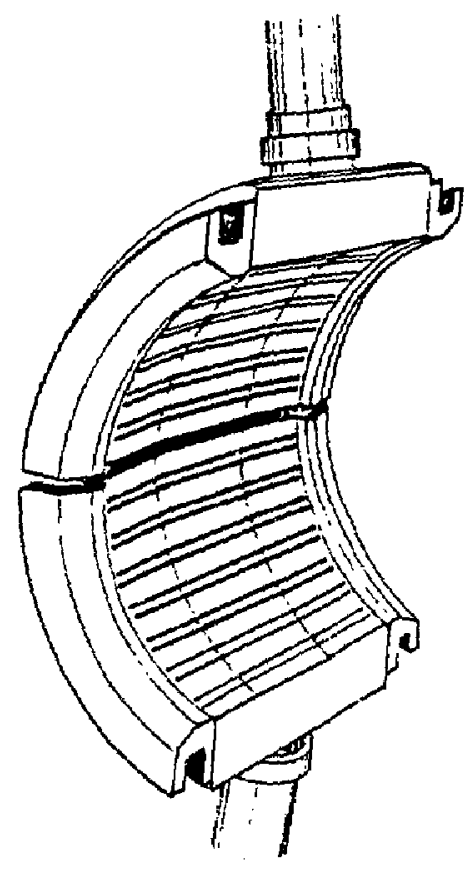

*64\%0768

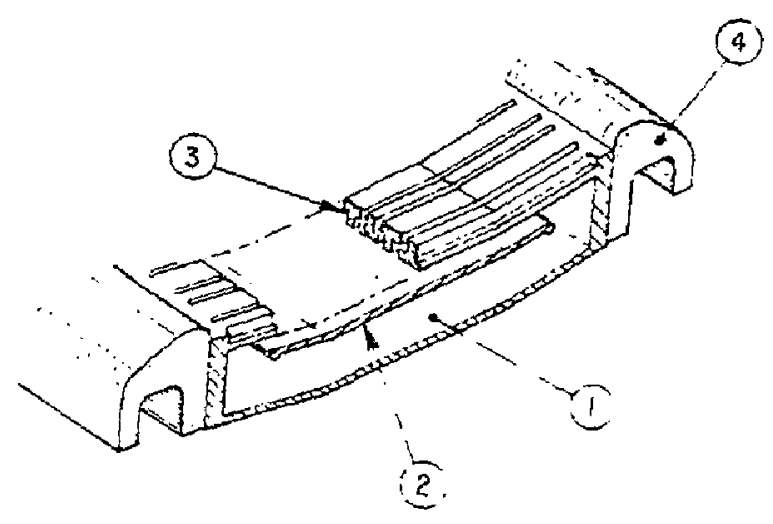

Fig. 3 

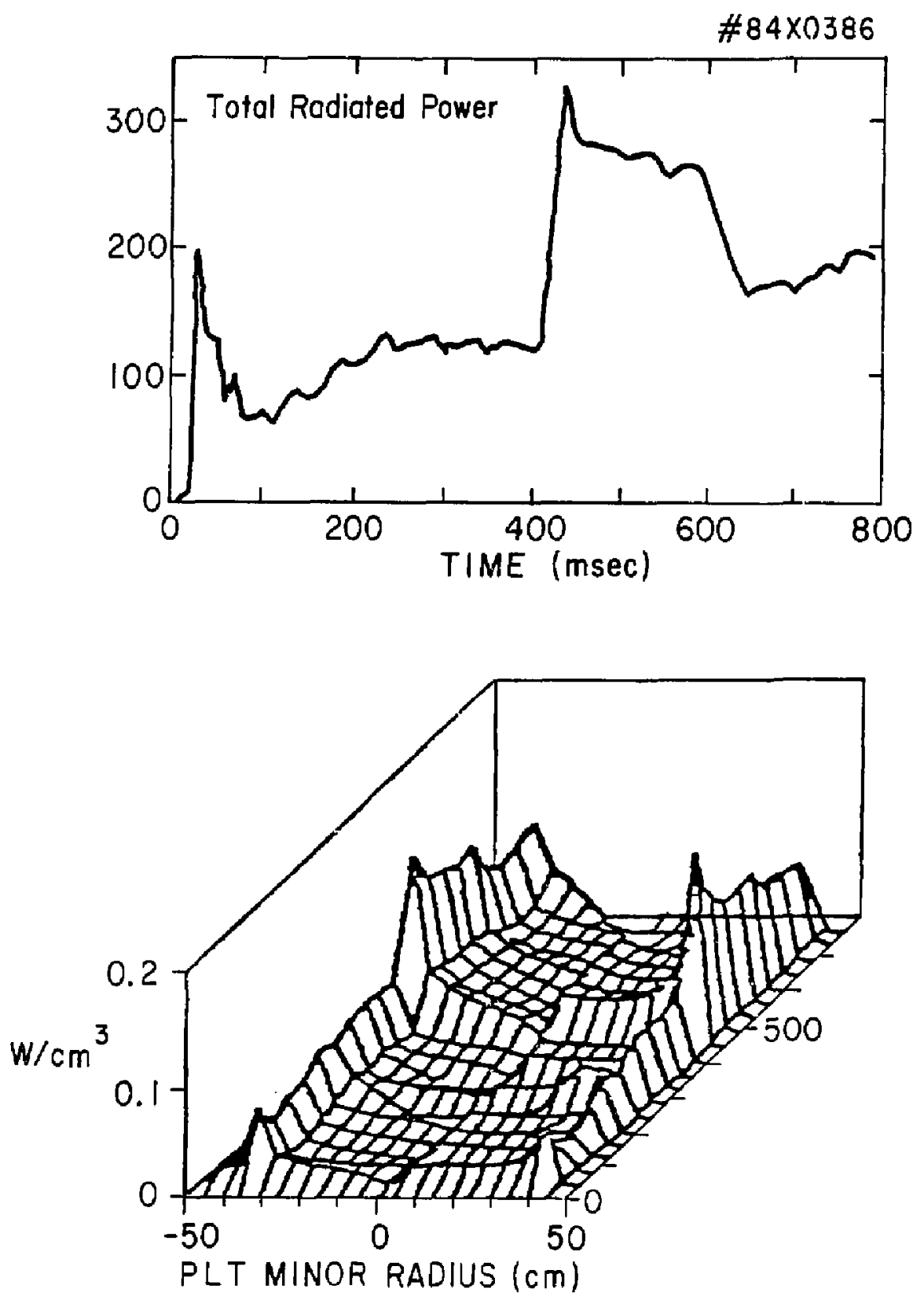

Fig. 4 

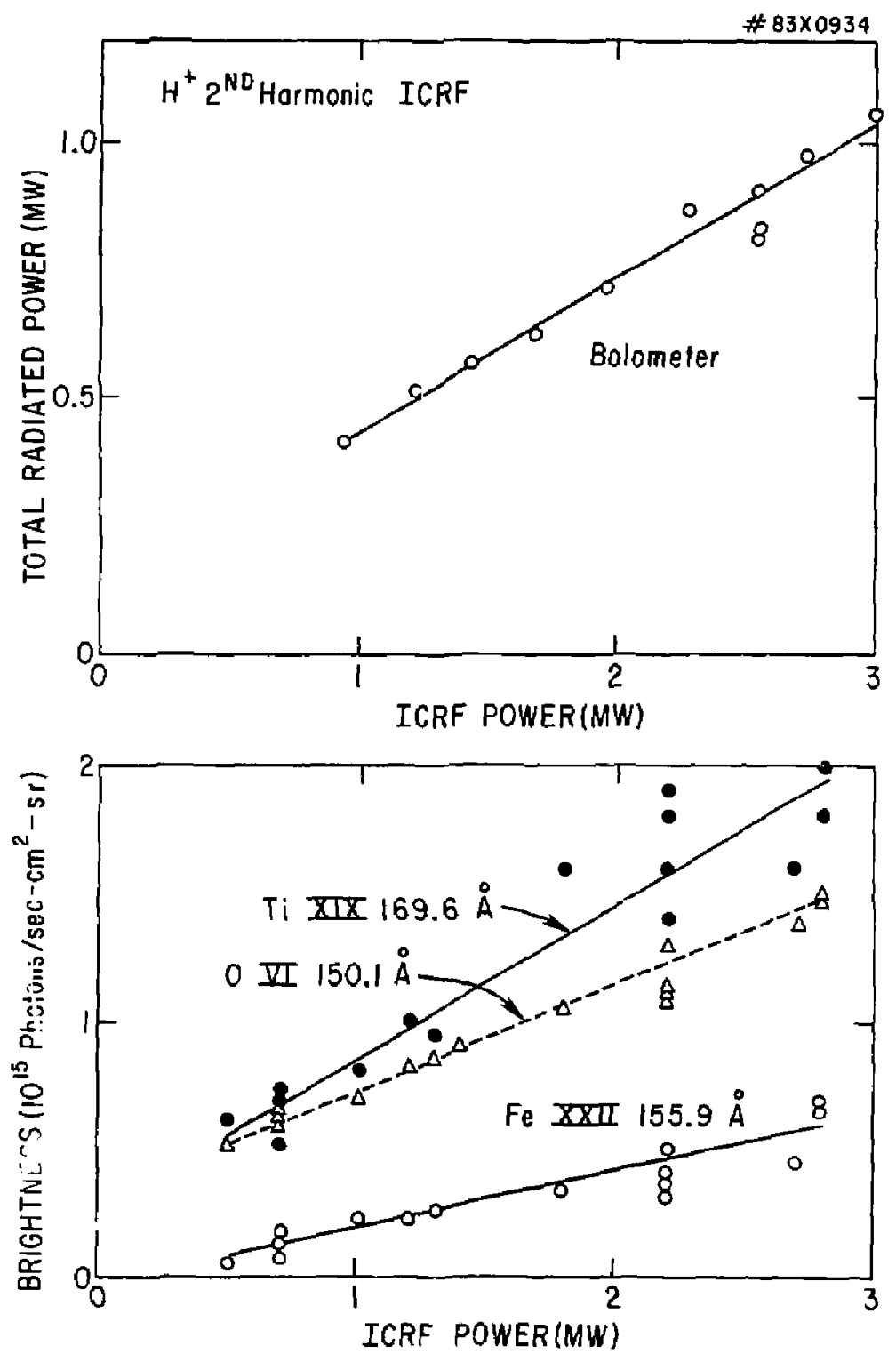

Fig. 5 


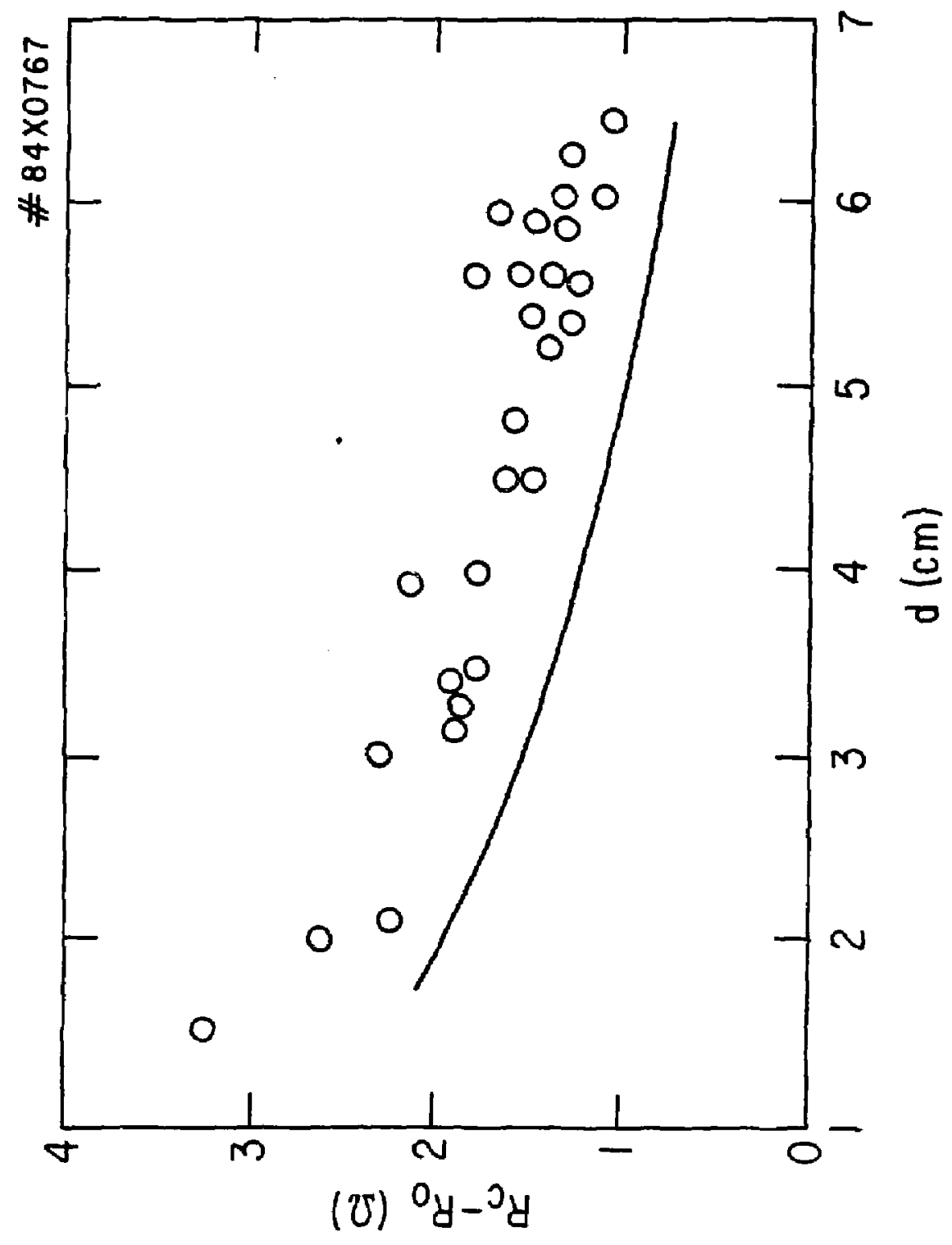




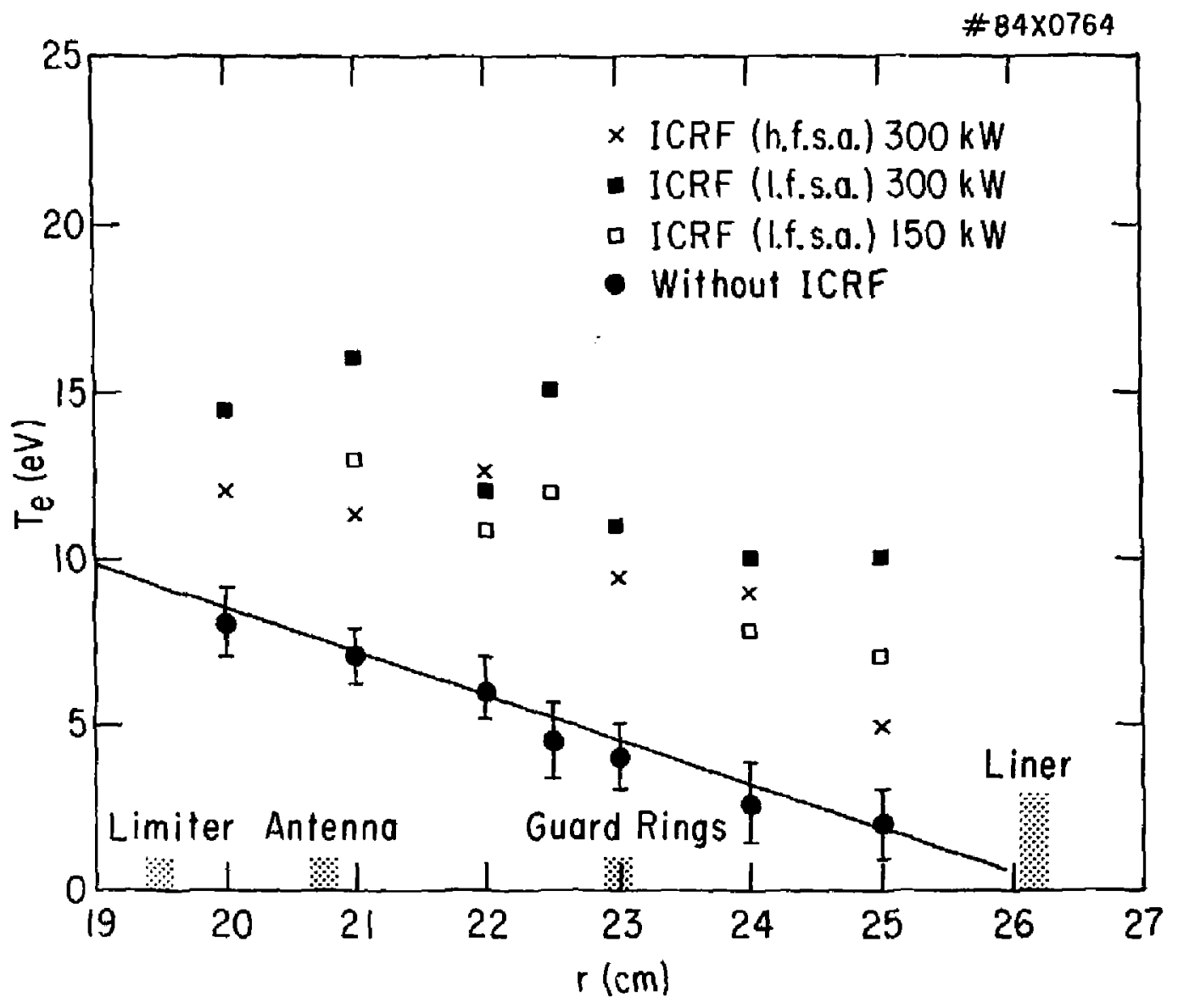

$\stackrel{\omega}{\omega}$ 


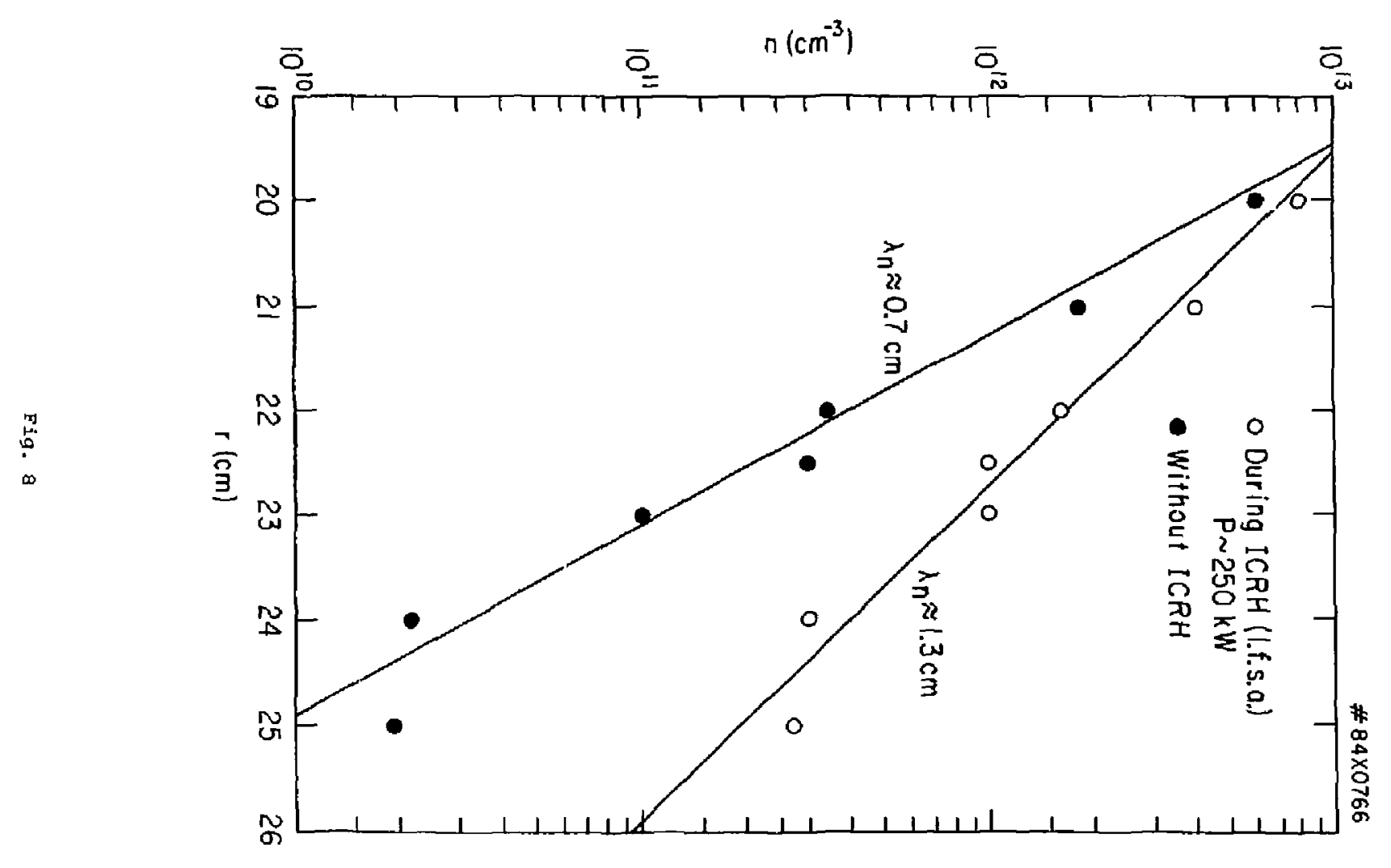



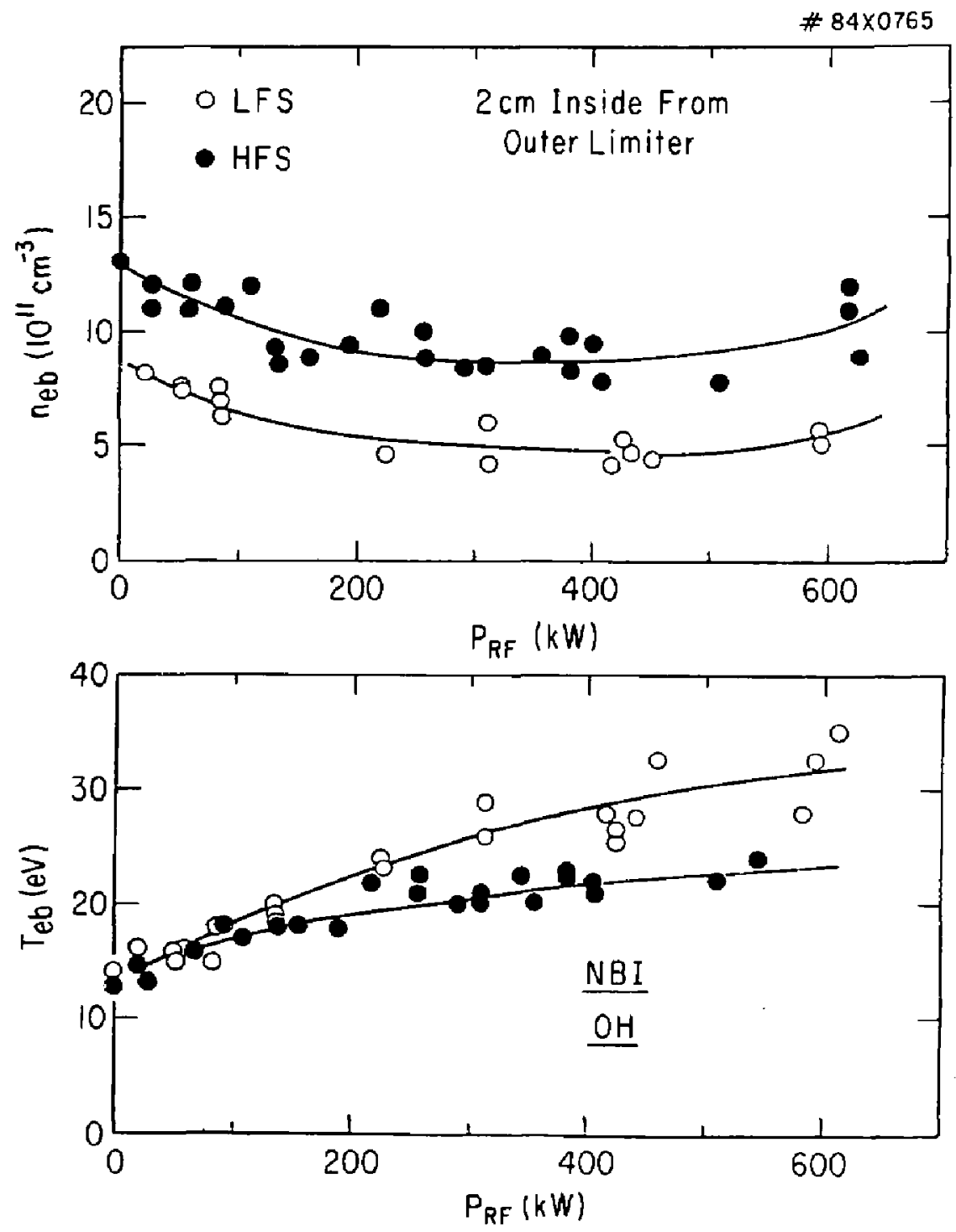

Fig. 9 


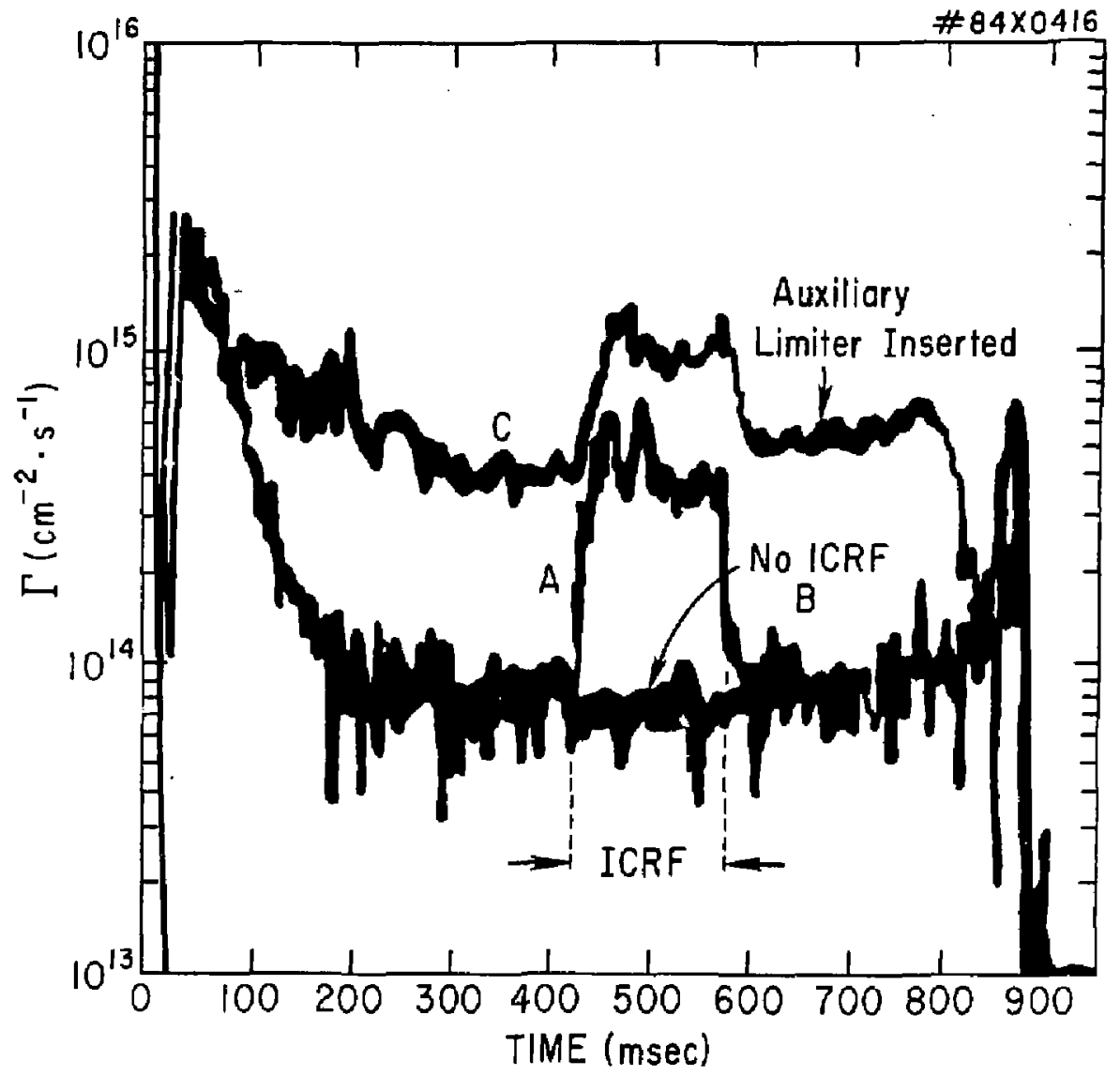

Fig. 10 


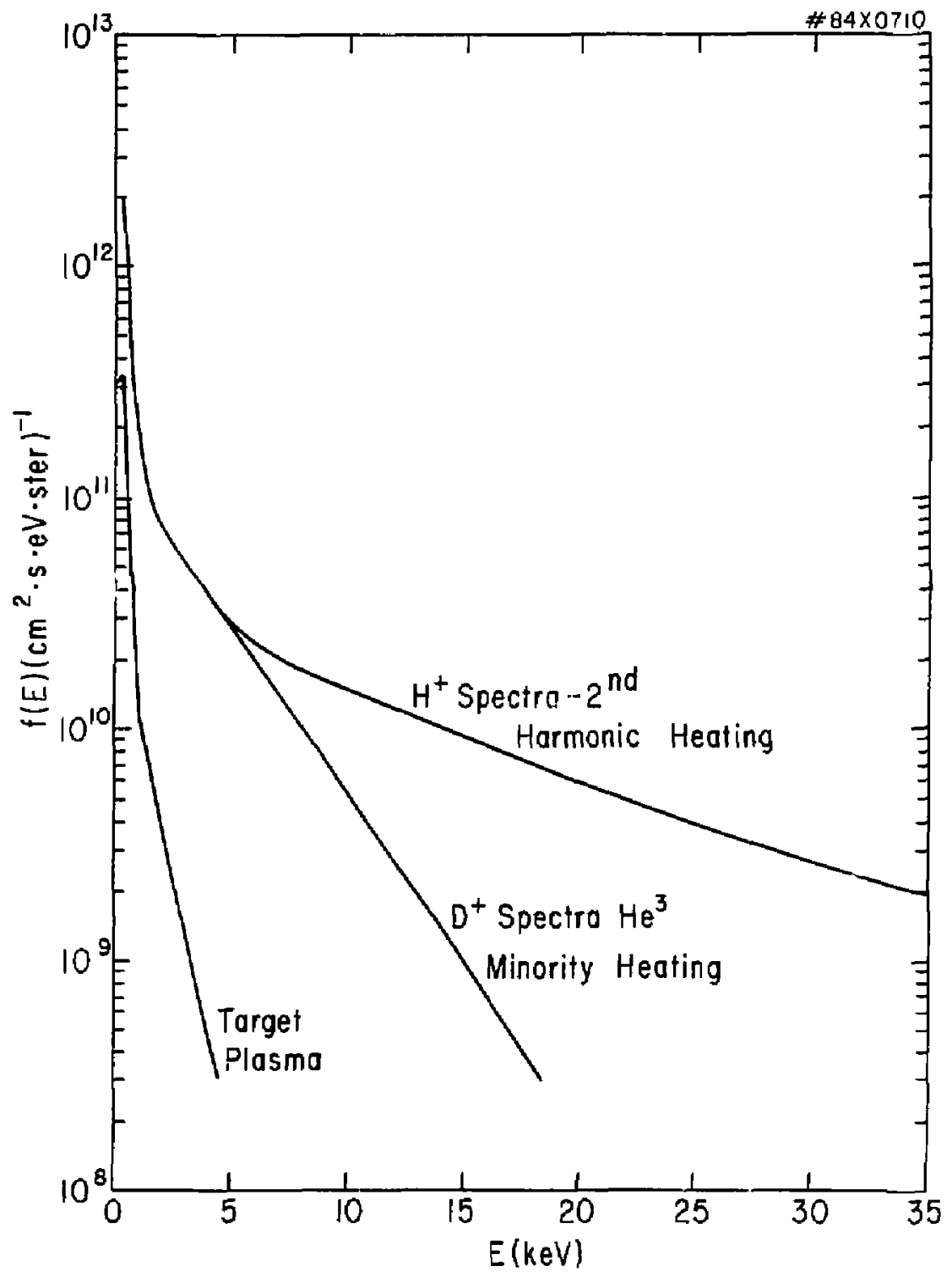

Fig, 11 


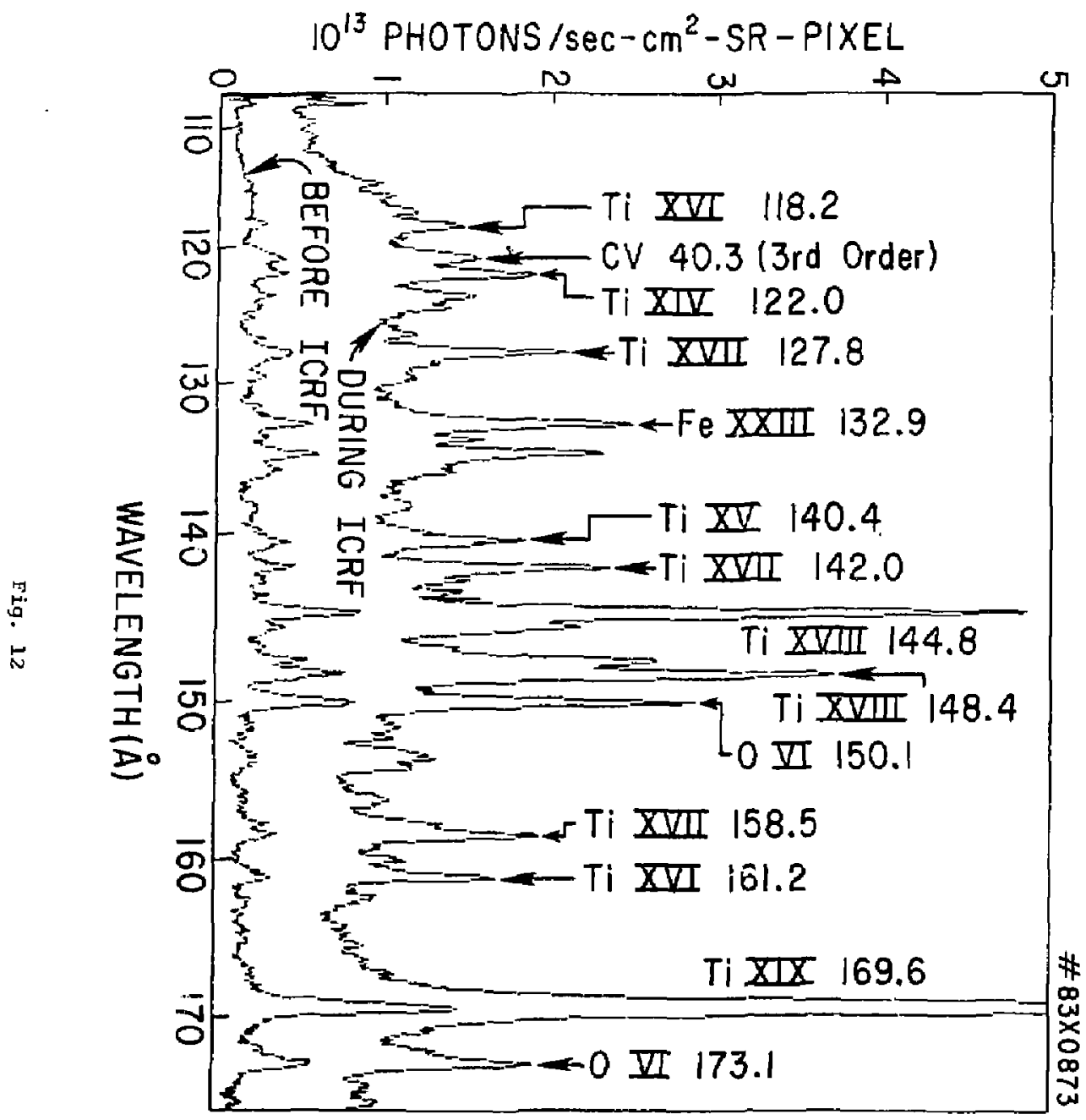




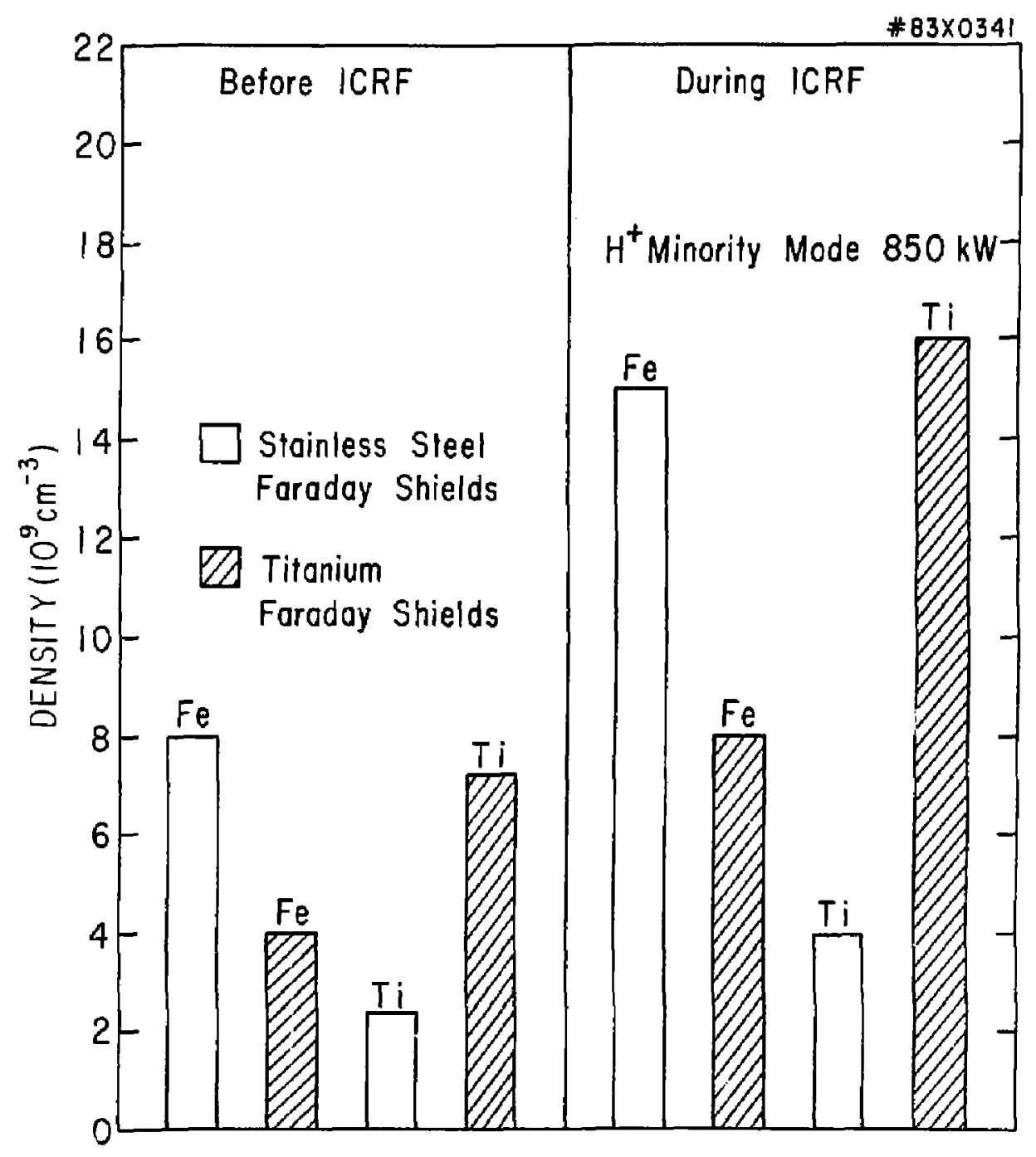

Fig. 13 
\#84X0708

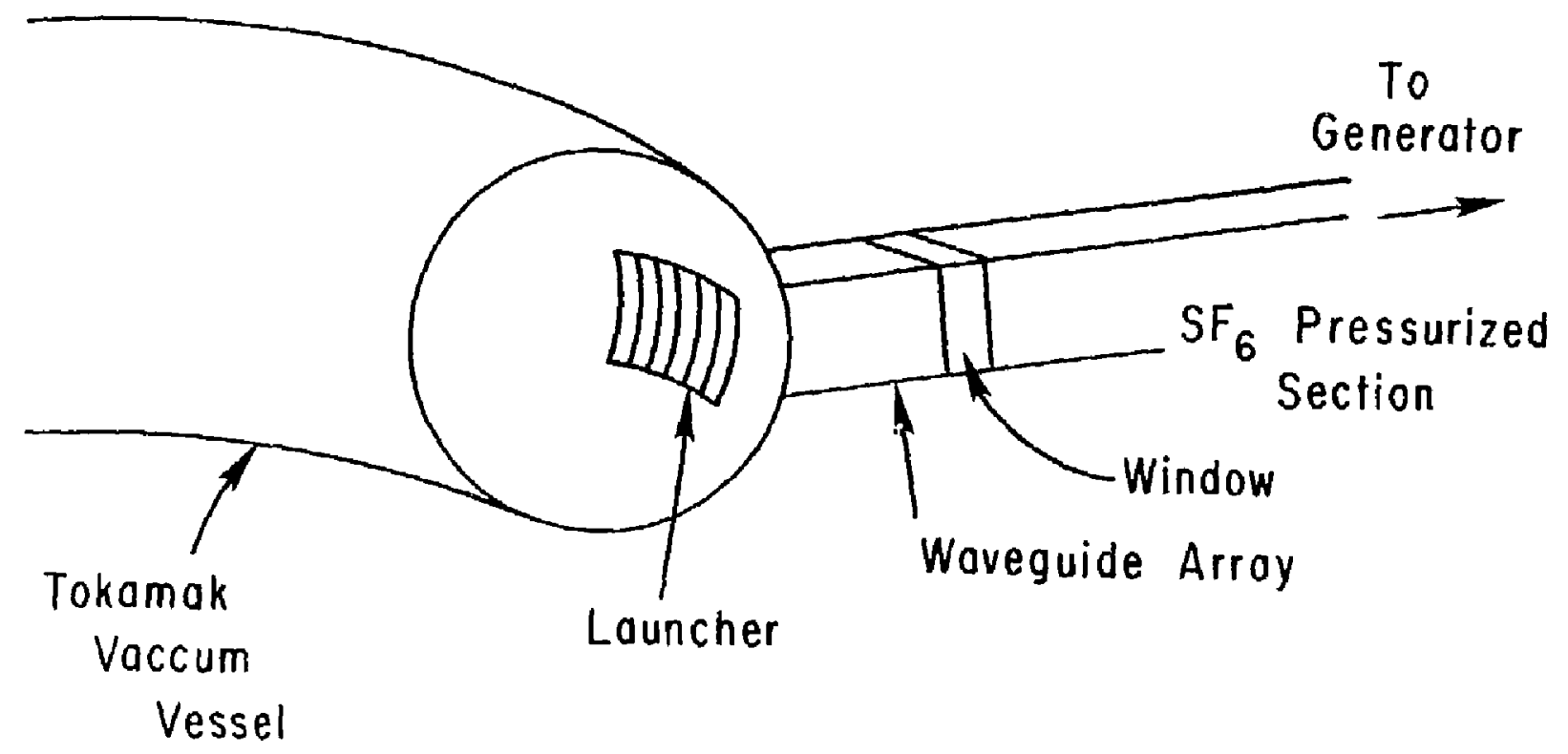




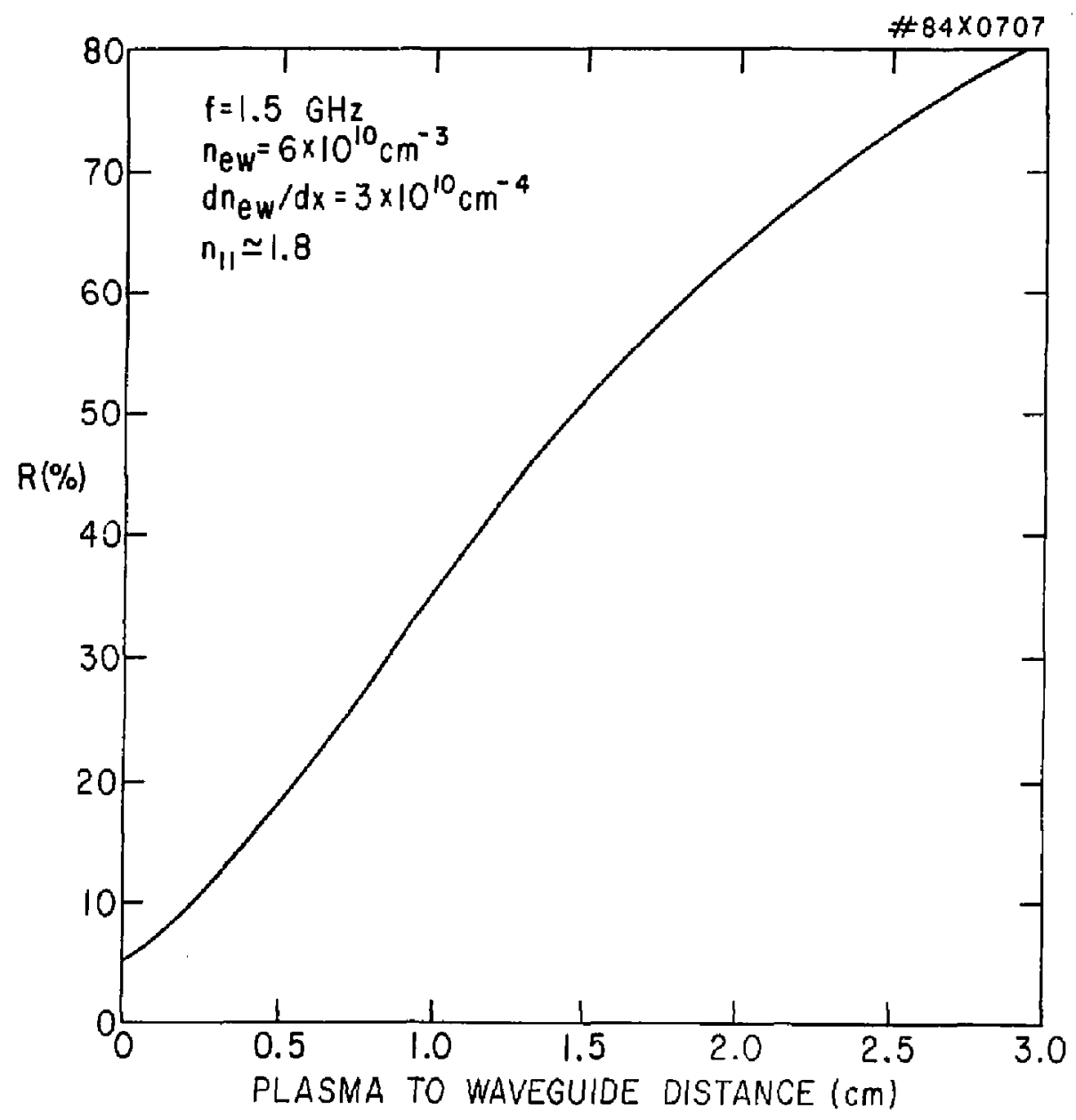

Fig. 15 

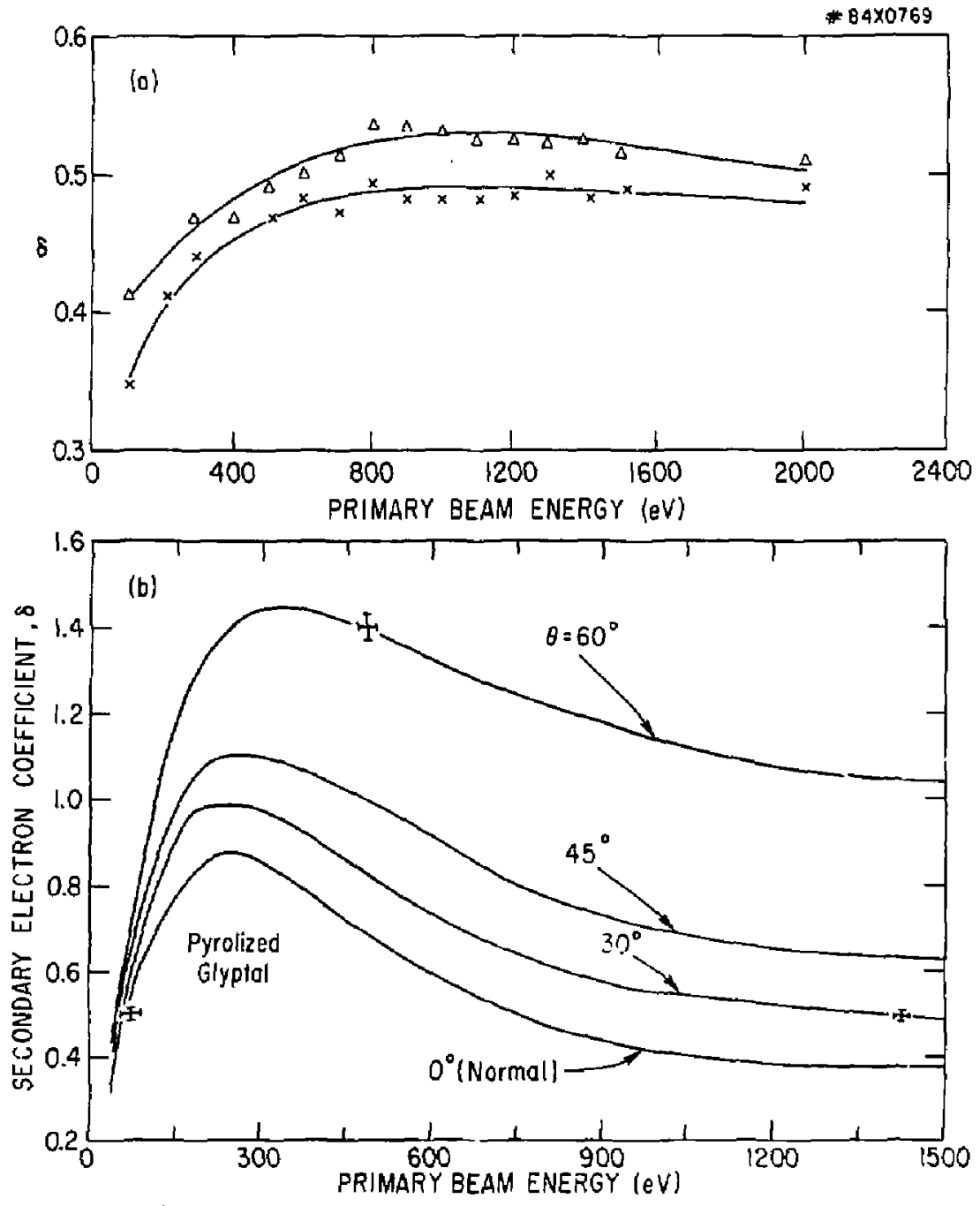

Fig. 16 


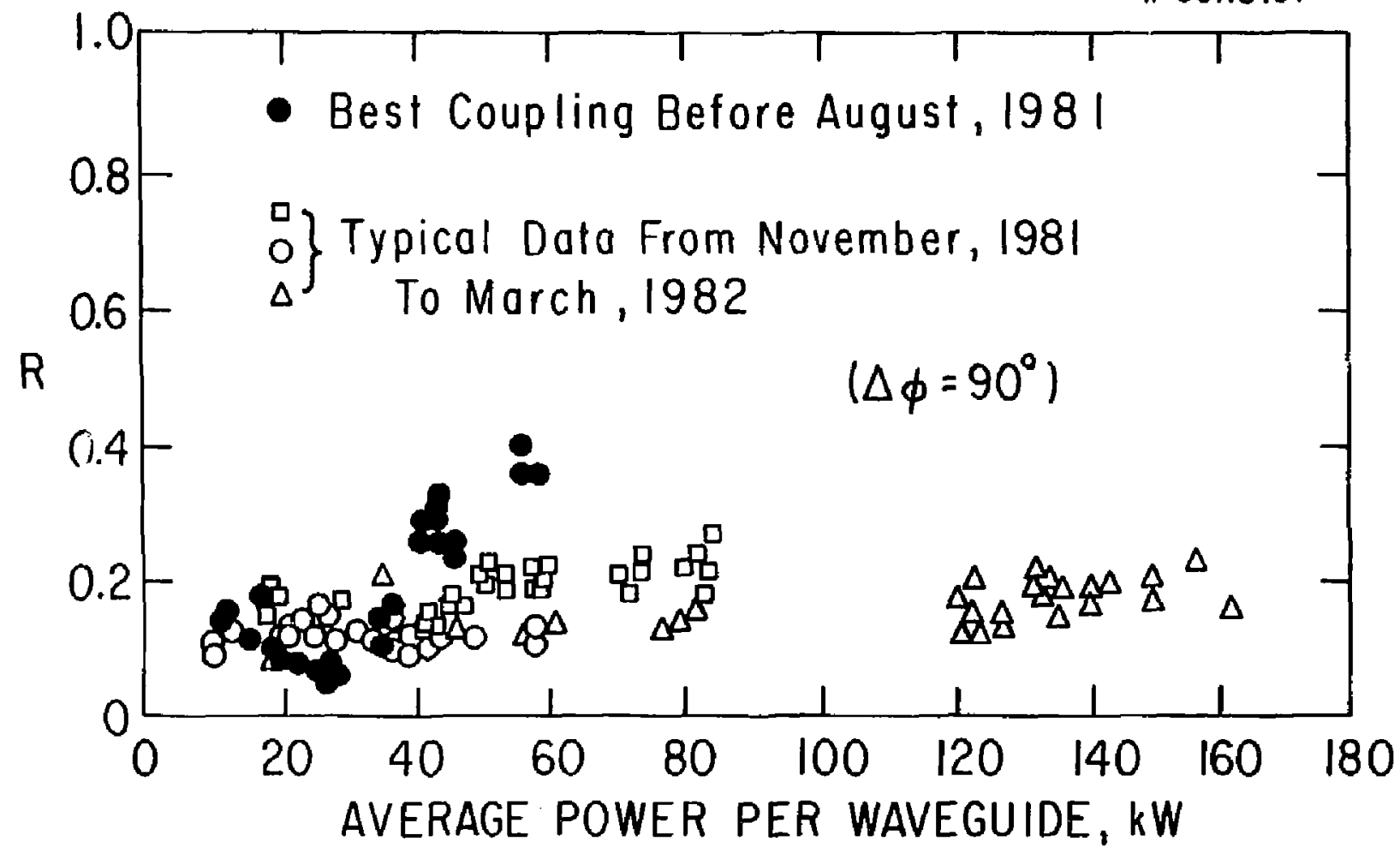


\# $84 \times 0704$
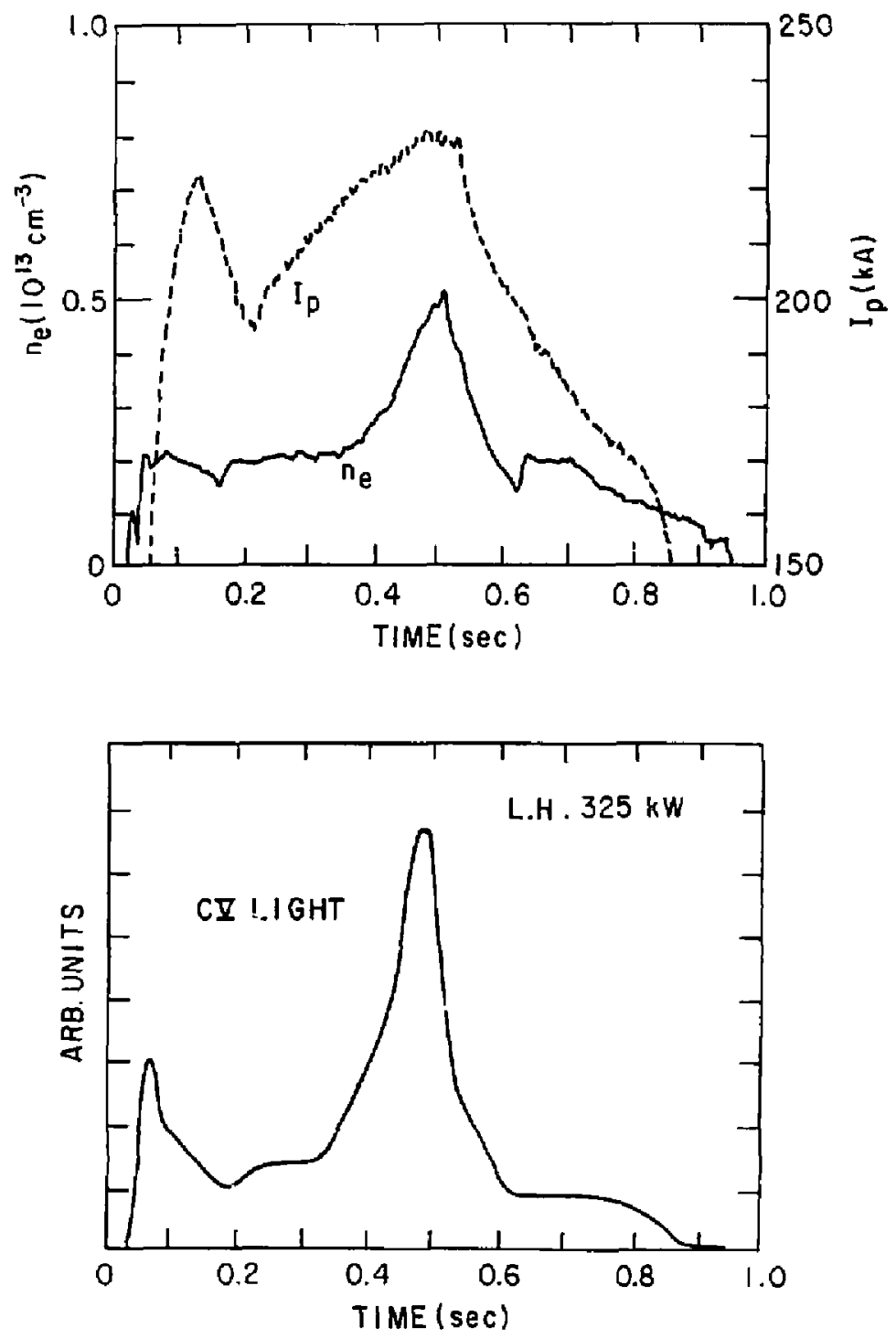

Fig. 18 


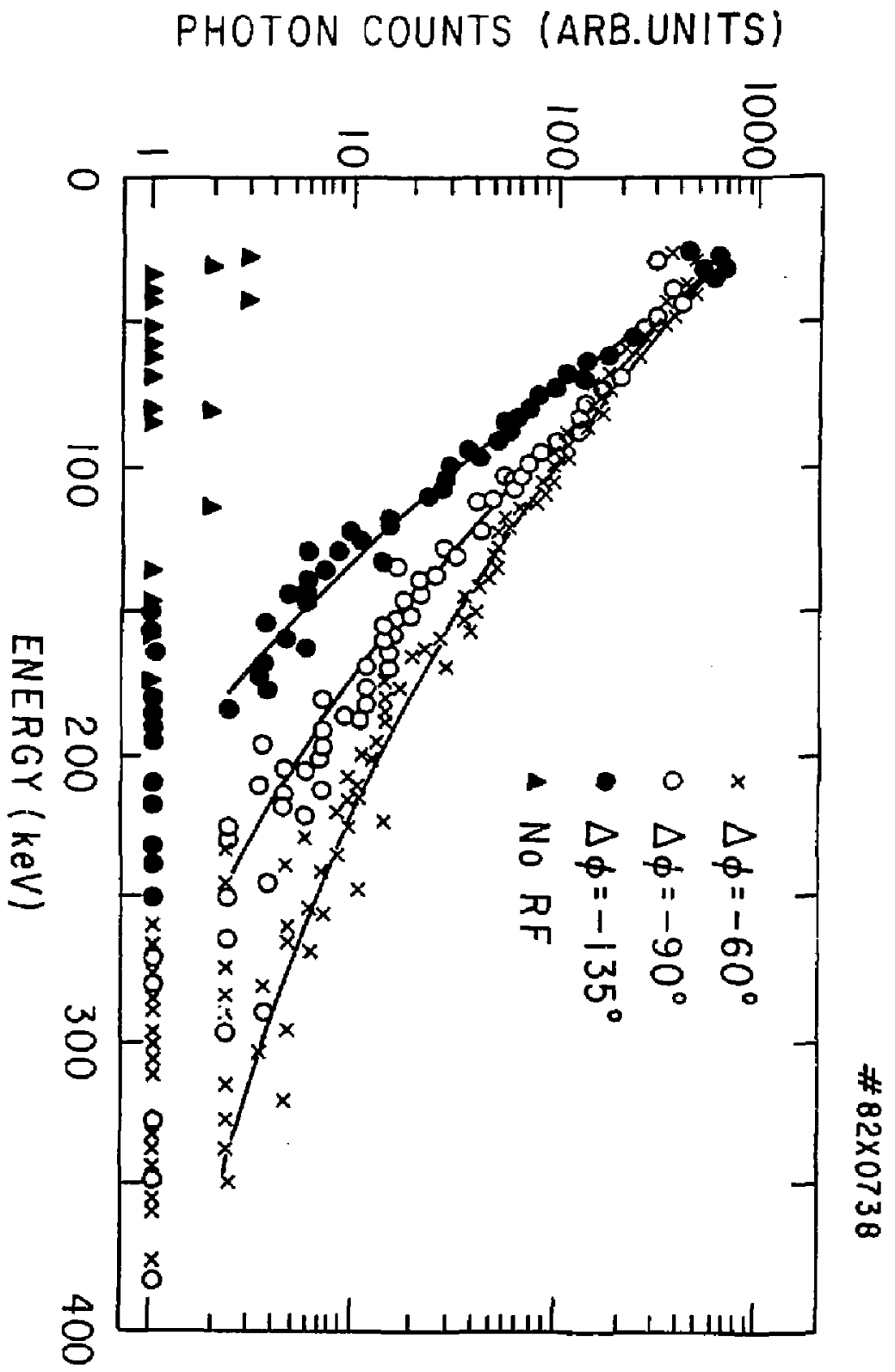




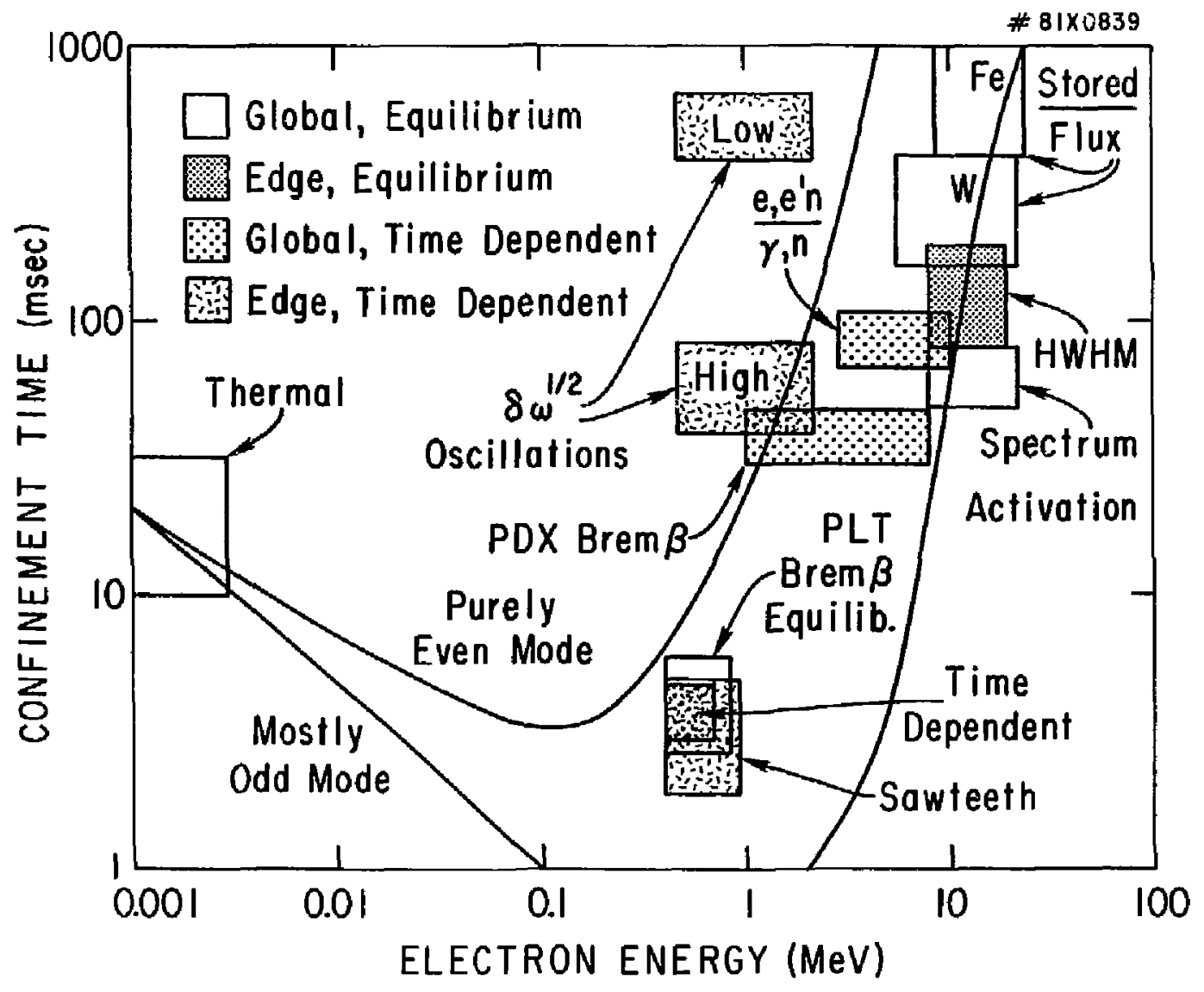




\section{EXTERMAL DISTRIBUTION IN AODITION TO TIC UC-20}

PIastre Res Leb, Austro met'I Unjy, Australia Dr. Fronk J. Pooloni, Unlv of mollongong, Austrat iA Prof. 1,R, Jones, fllindors Unlv., Australia Prof. M.H. Erennon, Unlv Syonoy, NUSTRUL IA Prof. F. Cap, Inst theo Phys, Austria

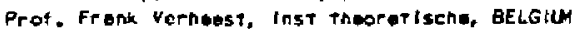
Dr. D. Falumbo, Dg XII fuslon Prog, eEloluH Ecole Roys le Militaira, Lab de Phys Plasmes, BELGILA Or. F.H. Sakanaka, Untr Estadual, GRAZIL Dr. C.R. James, Untw of Al berto, CANAJA Prot. J. Teichment, Univ of montreal, Cakhoh Dr. H.M. Skersgard, Univ of Sasketchmah, CANkDA Pros. S.R. Srmenl vasen, UnI werslty of Calgary, CANABA Prof. Tuoor w. Jonnston, IMR5-Energte, CNinaA Dr. Hannes Barnaro, Untr Airitisn Collumbla, CANADA D.r. M.P. Bechynski, MB Tochnologi us, Inc., CNHDA Znengu Li, SW Inst Physles, CHINA Libren, Tsing hue University, CHIMh Librerlan. Institute of Physlcs, CHINA Inst Plogmo Phys, acocemla Sinies, CHInk Dr. Peter Lukec, Komenskaho tinly, CZEChOsLovakia Tne bibrorlan, Cul hem Laboratory. EMGLAND Prot. Schetzman, Observatoire de Hice, FRAMCE J. RadeT, CEN-EPG, FRANCE

eM Dueos Ltbrory, AM Oupss LIBrery. FRAKCE Dr. Tom Mual, Acedemy Bl al lagraphic, hOHG kONS Frogr int LItrary, Cant Res Inst Phys, HuweAfy Dr. S.K. Trehen. Panjet UnIverslty, IHDiA D.r. Indra, manen Lel Dos. Baneros Hineu Univ, IMDIA D.r. L.K. Chevae, South Gujorat UnIr, INDIA Dr. R.K. Chnojiani, Yor Ruehl Morg. INDIA P. Kow, Physical Research Lob, IMDIA DF. PhJillo Rosenau, Israed Inst Tath, ISRAEL Prof. S. Cupormen, Tel Ayiv University, ISRaEL Prot. G. Rostagnl, Univ DI Podove. ITaly Liorarlon, Int'I Ctr Theo Fhys, ITALY MIss clello De Pelo, Assoc EURATOH-OUEN, ITALY Blolioteca, del CTR EURATOM, ITALY Dr. H. Yamto, Tosnibe Fes b Dev, JaPay Prot. M+ Yosnlkms, JAERI, Toksi Res Est, LAPAN Prot. T. Uenlda, Unlversity of Tokyo, JNPAN Reseerch Infa Center. Nogoro Unlwerslty. JAPAN Frot. Kroji Nisnikgme, Unir of Hirosh Jmb, JAPAN Pret. Sigeru Mort, JAERT, JAPAN LIbrary, Kysto University, JAPAN Prot. Iehiro Xewskami, NIhen UnIv, JAPAN Prot. Setashl Itoh, Kyushy University, JAFAN Tech Info Division, Korbe Atopla Energr. KOREA Or, R, Englano, Clvoud Unluorsiterla, MEXICO Blollotheok, Forrl Inst Yoor Plasma, HETHERLANDS Prot. B.5. Llley, Untuersity af waikato, NEW ZEALAND Dr. Suresh C. Shoma, Unlw of Colober. NIGERIA
Prot. J,A,C. Cobral, Inst Superlor Teeh, PORTUGal Dr. Octoulan Petrus, ALI CLRA UnImersity, ROMANIA Prot. H.A. Hellioerg, Unlversity of Notol, SO AfRICA Dr. Johen de VIIIllers, Atomlc Enorgr Bd, SO AFRICA Fusion OlY. LIbrory. JEN, SPAIN

Prot, Hans wilheimoon, Chalmers Un iv Taen, SWEDEN or. Lennert Stentlo, Un ivarslty of UMEA, SWEDEN LIbrary. Royer Inst Toch, SWEDEN

Dr. Erik T. Karison, UPpsalo Uniuars lTot. SWEDEN Centre de Recharehasen, Eeole Polvtech Fod, SWITERLAND D. W.L. Malsa, Mat'l Bur Stane, USA

Dr. W.M. Stacoy, Goorg Inst Tach, USA

Dr. 5.7. Nu, Un I Al A Coma, USA

Prot, Marman L. Olesan, Unlv 5 Flor ldo, USA Dr. Benjamin Ma, lowe 5tata Unly, U5A Prof. Mogna Kristlansen, Texas Teen Univ, USA Dr. Roymond Askm, Auburn UnIv, USA Dr. Y.T. Tolok, Knarkov Phys Toch Ins, IS5R Dr. D.D. Ryutov. SIberien Aciod SCI, USSR Dr, G,A, El lseev, Kurenotor InstITUTA, USSR Dr. V.A. Glukhlkh, Inst Electro-inysleal, US5R Institute Gen. Physies, LisR

Prot. T. S. Soyd, UnIr Colloge $N$ We tes, Males Ur. K. Sentinghar, Runt Unl marsitat, N. GePAMT Nuclaar fias Estad, Jullat LTO. W. GERMANY Llbrarlan, Max f hanck Institut, M. GERanar Dr. H.J. Kasplar, Unlvarsity STutTgarT, W. GEFAN Blollothok, Inst Plasidotorchung, $M$, EePaNy 